\title{
Superatomic $\mathrm{Au}_{25}\left(\mathrm{SC}_{2} \mathrm{H}_{5}\right)_{18}$ Nanocluster under Pressure
}

\author{
Qing Tang ${ }^{\dagger}$, Fuhua $\mathrm{Li}^{\dagger}$ and De-en Jiang*,* \\ ${ }^{\dagger}$ School of Chemistry and Chemical Engineering, Chongqing Key Laboratory of Theoretical and \\ Computational Chemistry, Chongqing University, Chongqing 401331, China \\ *Department of Chemistry, University of California, Riverside, California 92521, United States \\ * To whom correspondence should be addressed. E-mail: djiang@ucr.edu
}

\begin{abstract}
The last decade has witnessed significant advances in the synthesis and structure determination of atomically precise metal nanoclusters. However, little is known about the condensed matter properties of these nanosized metal nanoclusters packed in a crystal lattice under high pressure. Here using density function theory calculations, we simulate the crystal of a representative superatomic gold cluster, $\mathrm{Au}_{25}(\mathrm{SR})_{18}{ }^{0}\left(\mathrm{R}=\mathrm{C}_{2} \mathrm{H}_{5}\right)$, under various pressures. At ambient conditions, $\mathrm{Au}_{25}\left(\mathrm{SC}_{2} \mathrm{H}_{5}\right)_{18}{ }^{0}$ clusters are packed in a crystal via dispersion interactions; being a 7e superatom, each cluster carries a magnetic moment of $1 \mu_{\mathrm{B}}$ or one unpaired electron. Upon increasing compression (from 10 to $110 \mathrm{GPa}$ ), we observe the formation of inter-cluster $\mathrm{Au}-\mathrm{Au}, \mathrm{Au}-\mathrm{S}$, and $\mathrm{S}-\mathrm{S}$ covalent bonds between staple motifs, thereby linking the clusters into a network. The pressure-induced structural change is accompanied by the vanishment of the magnetic moment and the semiconductor-tometal transition. Our work shows that subjecting crystals of atomically precise metal nanoclusters to high pressures could lead to new crystalline states and physical properties.
\end{abstract}

Keywords: superatoms; ligand-protected gold nanoclusters; crystal structure; high pressure; density functional theory; cluster-cluster interactions 


\section{Introduction}

High-pressure studies have enriched the structural chemistry of compounds and led to unusual properties such as high-(room)-temperature superconductivity, ${ }^{1,2}$ metal-tosemiconductor transition, ${ }^{3}$ and superfluidity. ${ }^{4}$ In recent years, researchers have subjected many hydrogen-containing substances $\left(\mathrm{H}_{2},{ }^{4} \mathrm{SiH}_{4},{ }^{5} \mathrm{H}_{2} \mathrm{~S}^{1,6}\right.$, etc. $)$ and other inorganic systems $\left(\mathrm{He},{ }^{7} \mathrm{Li},{ }^{3,8,9} \mathrm{LiN}_{3},{ }^{10} \mathrm{Si}_{1}{ }^{11} \mathrm{SiO},{ }^{12} \mathrm{SiO}_{2}{ }^{13}\right.$, etc. $)$ under high pressures, finding intriguing chemical and physical properties. ${ }^{14,15}$

In the past decade, the ligand-protected metal nanoclusters, especially the thiolated gold nanoclusters, have attracted great interest as a novel type of functional nanomaterials. ${ }^{16-19}$ Due to their extraordinary stability, interesting structural and physicochemical properties, these nanoclusters can be potentially applied in diverse fields, including catalysis, ${ }^{20-23}$ biosensing, ${ }^{24-27}$ drug delivery, ${ }^{28,29}$ luminescence, ${ }^{30,31}$ and molecular electronics. ${ }^{32-34}$ Researchers were also interested in the mechanical response of the crystal of atomically precise nanoclusters. ${ }^{35}$ But so far only a couple of experimental studies have explored their high-pressure properties. Gu et al. ${ }^{36}$ reported the first highpressure optical study of a series of fcc and bitetrahedral nanoclusters, including $\mathrm{Au}_{21}(\mathrm{SR})_{12}, \mathrm{Au}_{28}(\mathrm{SR})_{20}, \mathrm{Ag}_{28} \mathrm{Pt}(\mathrm{SR})_{18}, \mathrm{Au}_{24}(\mathrm{SR})_{20}$, and $\mathrm{Au}_{14} \mathrm{Cd}(\mathrm{SR})_{12}$. They observed a red shift in the absorption onset with increasing pressure up to $\sim 12 \mathrm{GPa}$ in all the studied ulatrasmall nanoclusters and an up to 200 -fold enhancement in the photoluminescence at pressures around $7 \mathrm{GPa}$. In another work, Quan et al. ${ }^{37}$ probed the pressure response of a silver sulfide cluster crystal $\left(\left[\mathrm{Ag}_{50} \mathrm{~S}_{7}\left(\mathrm{SC}_{6} \mathrm{H}_{4} \mathrm{~F}\right)_{36}(\mathrm{dppp})_{6}\right]\right)$, and observed a noticeable decrease of band gap accompanied by visual thermochromism and piezochromism from ambient conditions to $7.5 \mathrm{GPa}$. 
The recent pioneering experimental studies of atomically precise metal nanoclusters under high pressure are expected to draw more attention and efforts to understand how atomically precise metal nanoclusters change their states and properties with pressure. Especially, one is interested in their behavior at even higher pressures such as tens of or even 100s of GPa. Another question is how their electronic structure would evolve with pressure from the superatomic perspective. To address these questions, here we use density functional theory (DFT) calculations to simulate a crystal of superatomic $\mathrm{Au}_{25}(\mathrm{SR})_{18}$, the most studied atomically precise metal nanocluster, ${ }^{38}$ under pressures up to $110 \mathrm{GPa}$. We chose the experimental crystal structure of the neutral $\mathrm{Au}_{25}\left(\mathrm{SC}_{2} \mathrm{H}_{5}\right){ }_{18}{ }^{0}$ cluster as the starting model for DFT simulations, for its short ligand ${ }^{39}$ and to avoid complication from counterions.

\section{Computational methods}

DFT calculations were performed using the Vienna $a b$ initio simulation package (VASP version 5.4.4). ${ }^{40}$ The ion-electron interaction is described with the projector augmented wave (PAW) method. ${ }^{41}$ Electron exchange-correlation is represented by the functional of Perdew, Burke and Ernzerhof (PBE) of generalized gradient approximation (GGA). ${ }^{42}$ A cutoff energy of $500 \mathrm{eV}$ was used for the plane-wave basis set. The Brillouin zone was sampled by a Monkhorst-Pack $k$-point mesh of $5 \times 5 \times 5$ for geometry optimization and $11 \times 11 \times 11$ for static electronic structure calculation. The convergence threshold for structural optimization was set to be $10^{-5} \mathrm{eV}$ in energy and $0.01 \mathrm{eV} / \AA$ in force. The van der Waals interactions were considered using the empirical correction in Grimme's scheme (DFT-D3). ${ }^{43}$ 
Experimental crystal structure of $\mathrm{Au}_{2} 5\left(\mathrm{SC}_{2} \mathrm{H}_{5}\right) 18^{0}$ at ambient conditions ${ }^{39}$ was used as the initial structure in our DFT model. The crystal has a centrosymmetric triclinic symmetry (space group $P \overline{1}$ ) with the following parameters: $\mathrm{a}=13.773 \AA, \mathrm{b}=13.886 \AA$, $\mathrm{c}=14.152 \AA, \alpha=104.38^{\circ}, \beta=101.41^{\circ}, \gamma=119.29^{\circ}$. Like other typical $\mathrm{Au}_{25}(\mathrm{SR})_{18}$ clusters, $\mathrm{Au}_{25}\left(\mathrm{SC}_{2} \mathrm{H}_{5}\right)_{18}$ is composed of an inner $\mathrm{Au}_{13}$ icosahedral core protected by six $\left(\mathrm{SC}_{2} \mathrm{H}_{5}\right)$ $\mathrm{Au}-\left(\mathrm{SC}_{2} \mathrm{H}_{5}\right)-\mathrm{Au}-\left(\mathrm{SC}_{2} \mathrm{H}_{5}\right)$ dimeric staple motifs. The intra-cluster $\mathrm{Au}-\mathrm{Au}$ distances from the DFT optimization ( $\mathrm{Au}_{\text {center- }}-\mathrm{Au}_{\text {shell }}: 2.85 \AA$; $A u_{\text {shell }}-\mathrm{Au}_{\text {shell }}: 2.99 \AA$; $A u_{\text {shell }}-\mathrm{Au}_{\text {staple: }} 3.29 \AA$ ) agree very well with the experiment (Aucenter-Aushell: $2.79 \AA$; Aushell-Aushell: $2.94 \AA$; Aushell$\mathrm{Au}_{\text {staple: }} 3.18 \AA$ ). The inter-cluster $\mathrm{Au}-\mathrm{Au}$ distance is about $7 \%$ underestimated by DFT $(3.82 \AA)$ than the experiment $(4.11 \AA)$, likely due to two factors: (i) we fixed the lattice parameters to the experimental values during DFT optimization to maintain the cell shape for the subsequent pressurization simulations; (ii) the inter-cluster $\mathrm{Au}-\mathrm{Au}$ interaction is much weaker and therefore sensitive to the inter-cluster ligand-ligand interactions. We expect that the DFT description of the inter-cluster Au-Au distances would become more accurate, as the $\mathrm{Au}-\mathrm{Au}$ interactions are strengthened with the pressure.

Starting from the ground state structure of $\mathrm{Au}_{25}\left(\mathrm{SC}_{2} \mathrm{H}_{5}\right)_{18}$, the high-pressure structures were obtained by continuously and uniformly shrinking the volume or lattice constants of $\mathrm{Au}_{25}\left(\mathrm{SC}_{2} \mathrm{H}_{5}\right)_{18}$ : the lattice parameters a, $\mathrm{b}$ and $\mathrm{c}$ (Table 1) were scaled by the same factor, such that the crystal symmetry and the lattice ratios of c/a and b/a are kept fixed on compression. After each scaling, the atomic positions in the unit cell were reoptimized with fixed unit cell vectors; after convergence the pressure was then evaluated by computing the external force on the unit cell. Spin-polarized calculations with an initial ferromagnetic state were performed for the $\mathrm{Au}_{25}\left(\mathrm{SC}_{2} \mathrm{H}_{5}\right)_{18}$ crystal under different pressures. 
Table 1. Lattice parameters $(\mathrm{a}, \mathrm{b}, \mathrm{c})$ of the $\mathrm{Au}_{25}\left(\mathrm{SC}_{2} \mathrm{H}_{5}\right)_{18}$ crystal under various pressures. The angular parameters are kept at the same: $\alpha=104.38^{\circ}, \beta=101.41^{\circ}, \gamma=119.29^{\circ}$.

\begin{tabular}{|c|c|c|c|}
\hline \multirow{2}{*}{$\begin{array}{c}\text { Pressure } \\
(\mathrm{GPa})\end{array}$} & $\mathrm{a}$ & $\mathrm{3}$ & $\mathrm{c}$ \\
\cline { 2 - 4 } & 13.773 & 13.886 & 14.152 \\
\hline 0 & 12.395 & 12.498 & 12.737 \\
\hline 10 & 11.701 & 11.798 & 12.024 \\
\hline 25 & 11.047 & 11.137 & 11.350 \\
\hline 50 & 10.715 & 10.803 & 11.009 \\
\hline 80 & 10.427 & 10.514 & 10.715 \\
\hline 110 & & & \\
\hline
\end{tabular}

Table 2. Covalent and van der Waals radii of $\mathrm{Au}, \mathrm{S}, \mathrm{C}$ and $\mathrm{H}$ atoms, and their averages which are used to define the bond formation between two atoms. If the distance between two atoms is shorter than the sum of their average radii, we consider that a chemical bond is formed between the two atoms.

\begin{tabular}{c|ccc|cccc}
\hline \multirow{2}{*}{ Atom } & \multicolumn{4}{|c|}{ Radii $(\AA)$} & \multicolumn{4}{c}{ Bond-length cutoff $(\AA)$} \\
\cline { 2 - 8 } & Covalent & van der Waals & Average & Au & S & C & H \\
\hline $\mathrm{Au}$ & 1.44 & 1.66 & 1.55 & 3.10 & 2.96 & 2.79 & 2.34 \\
$\mathrm{~S}$ & 1.02 & 1.80 & 1.41 & - & 2.82 & 2.65 & 2.30 \\
$\mathrm{C}$ & 0.77 & 1.70 & 1.24 & - & - & 2.48 & 2.03 \\
$\mathrm{H}$ & 0.38 & 1.20 & 0.79 & - & - & - & 1.58 \\
\hline
\end{tabular}

\section{Results and discussion}

Crystal structure of $\mathrm{Au}_{25}\left(\mathrm{SC}_{2} \mathrm{H}_{5}\right)_{18}{ }^{0}$ at ambient pressures. As shown in Figure 1, the clusters in the crystal are weakly interacting with each other via vdW interactions among ethyl groups of the staple motifs (blue lines in Figure 1a,c): the shortest intermolecular 
$\mathrm{H} \cdots \mathrm{H}$ distance between ethyl groups is $2.07 \AA$ ( $\mathrm{d}_{1}$ in Figure 1c). The shortest inter-cluster $\mathrm{Au} \cdots \mathrm{Au}$ distance between two staple motifs is $3.82 \AA$ ( $\mathrm{d}_{2}$ in Figure $\left.1 \mathrm{~b}\right)$.

To define a criterion or distance cutoff for chemical bonding, we use the average of the covalent and vdW radii of an atom (Table 2): If the distance between two atoms is shorter than the sum of their average radii, a chemical bond is formed or there is chemical interaction between the two atoms. By our definition, there is no inter-cluster chemical

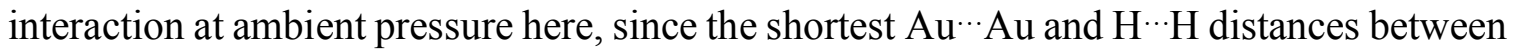
neighboring $\mathrm{Au}_{25}\left(\mathrm{SC}_{2} \mathrm{H}_{5}\right)_{18}$ clusters are much larger than the bond-length cutoff of the $\mathrm{Au}-$ $\mathrm{Au}(3.10 \AA)$ and $\mathrm{H}-\mathrm{H}(1.58 \AA)$ chemical interactions.
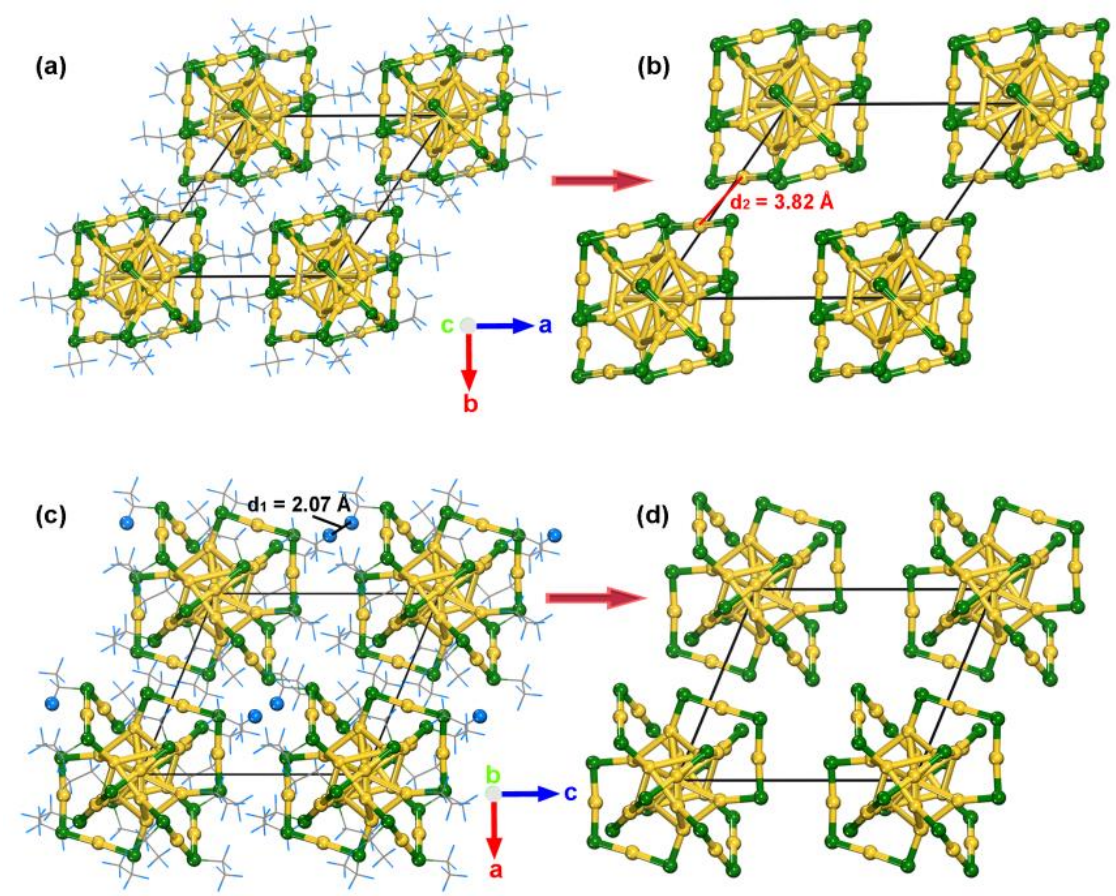

Figure 1. Ambient pressure structure of the crystal phase of $\mathrm{Au}_{25}\left(\mathrm{SC}_{2} \mathrm{H}_{5}\right)_{18}{ }^{0}$ cluster $(\mathrm{a}, \mathrm{c})$ and the corresponding Au-S framework omitting the ethyl $\left(\mathrm{C}_{2} \mathrm{H}_{5}\right)$ groups $(b, d)$, viewed along two different directions: $(\mathrm{a}, \mathrm{b})$ are projected along the c-axis; $(\mathrm{c}, \mathrm{d})$ are projected along the b-axis. Color code: Au, orange; S, green; C, gray; H, blue (lines with some highlighted balls). Same color code used subsequently. 
According to the superatom complex theory, ${ }^{44}$ the isolated neutral $\mathrm{Au}_{25}\left(\mathrm{SC}_{2} \mathrm{H}_{5}\right)_{18}$ cluster has 7 free electrons, which occupy the superatomic orbitals as $(1 \mathrm{~S})^{2}(1 \mathrm{P})^{5}$, thereby possessing an unpaired valence electron at the HOMO. This is consistent with our calculations: we found that the unit cell of $\mathrm{Au}_{25}\left(\mathrm{SC}_{2} \mathrm{H}_{5}\right)_{18}$ crystal, which contains just one formula unit of the cluster, has a net magnetic moment of $1 \mu \mathrm{B}$.

At 10 GPa. Figure 2 shows the Au-S framework of the compressed $\mathrm{Au}_{25}\left(\mathrm{SC}_{2} \mathrm{H}_{5}\right)_{18}{ }^{0}$ crystal structure at an external pressure of $10 \mathrm{GPa}$. One can clearly see that the inter-cluster distance decreases, leading to the formation of an inter-cluster $\mathrm{Au}-\mathrm{Au}$ bond of $3.09 \AA$ along the b-axis (Figure 2a,d) between the staple motifs, which joins the clusters to form a onedimensional (1D) nanowire along the b-axis (Figure 2c-e). The closest $\mathrm{Au} \cdots \mathrm{Au}$ contact between the 1D nanowires is about $3.48 \AA$ along the c-axis (Figure 2b). Interestingly, we found that the magnetic moment of the $\mathrm{Au}_{25}\left(\mathrm{SC}_{2} \mathrm{H}_{5}\right)_{18}$ crystal disappeared $\left(\mu_{\mathrm{B}}=0\right)$ at 10 GPa. This can be understood in that the unpaired electrons in each $\mathrm{Au}_{25}\left(\mathrm{SC}_{2} \mathrm{H}_{5}\right)_{18}$ cluster are now paired after forming the inter-cluster $\mathrm{Au}-\mathrm{Au}$ bonds, leading to the vanishing magnetic moment. In fact, the nanowire-like $1 \mathrm{D}$ polymeric chain of $\mathrm{Au}_{25}(\mathrm{SR}){ }_{18}{ }^{0}$ has been previously reported in the solid state of another neutral $\mathrm{Au}_{25}(\mathrm{SR}){ }_{18}{ }^{0}$ nanocluster capped by n-butanethiolates $(\mathrm{SBu})$ ligands. ${ }^{45}$ 
(a)

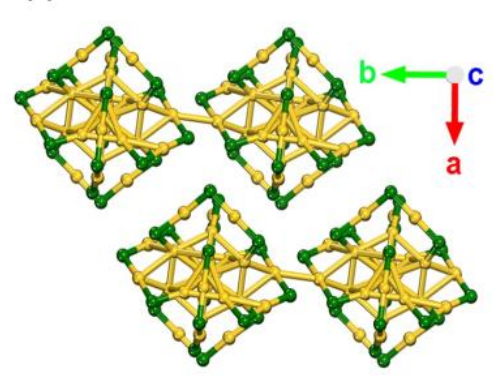

(b)

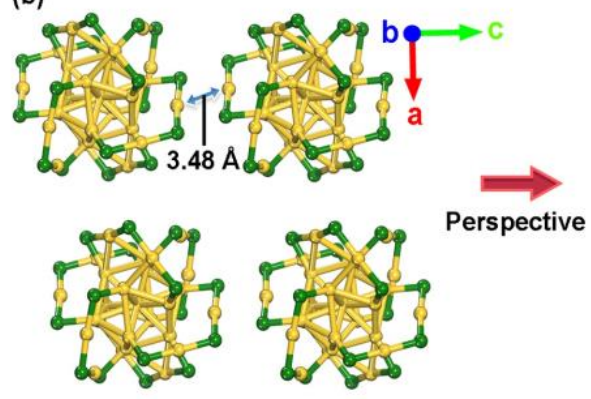

(c)

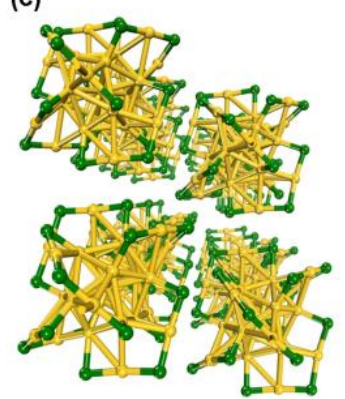

(d)

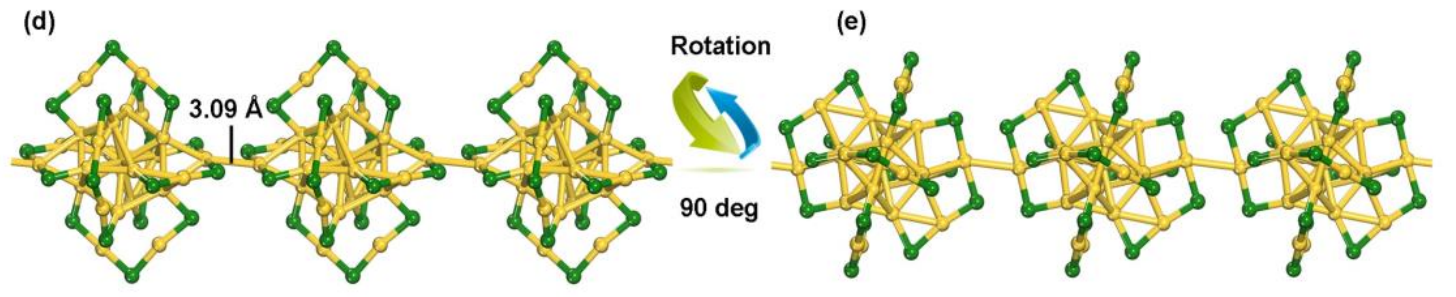

Figure 2. $\mathrm{Au}_{25}\left(\mathrm{SC}_{2} \mathrm{H}_{5}\right)_{18}$ crystal at $10 \mathrm{GPa}\left(\mathrm{C}_{2} \mathrm{H}_{5}\right.$ omitted for clarity): (a) viewed along the c-axis; (b) viewed along the b-axis; (c) perspective view of four 1D nanowires along the b-axis; (d, e) two different side views of the $\mathrm{Au}_{25}\left(\mathrm{SC}_{2} \mathrm{H}_{5}\right)_{18}$ nanowire and the inter-cluster $\mathrm{Au}$-Au linkages.

At 25 GPa. As the pressure further increases to $25 \mathrm{GPa}$, the inter-cluster $\mathrm{Au}-\mathrm{Au}$ bond between the staple motifs along the b-axis is further decreased to $2.96 \AA$ (Figure 3a). In addition, we observed newly formed inter-cluster $\mathrm{Au}-\mathrm{Au}$ bond of $2.90 \AA$ (Figure 3b) along the diagonal direction of the unit cell (namely, $\mathbf{a}+\mathbf{b}+\mathbf{c}$ or [111] direction) and inter-cluster Au-S bonds of $2.74 \AA$ along the c-axis (Figure 3c,d). In fact, the latter further forms a rectangle-shaped, four-membered ring between inter-cluster staple motifs. This indicates that from $10 \mathrm{GPa}$ to $25 \mathrm{GPa}$, the crystalline phase of $\mathrm{Au}_{25}\left(\mathrm{SC}_{2} \mathrm{H}_{5}\right)_{18}$ transitions from the stacked 1D nanowires to 3D inter-connected network. Similar to the case at $10 \mathrm{GPa}$, the compressed $\mathrm{Au}_{25}\left(\mathrm{SC}_{2} \mathrm{H}_{5}\right)_{18}$ at $25 \mathrm{GPa}$ has no unpaired electron. 

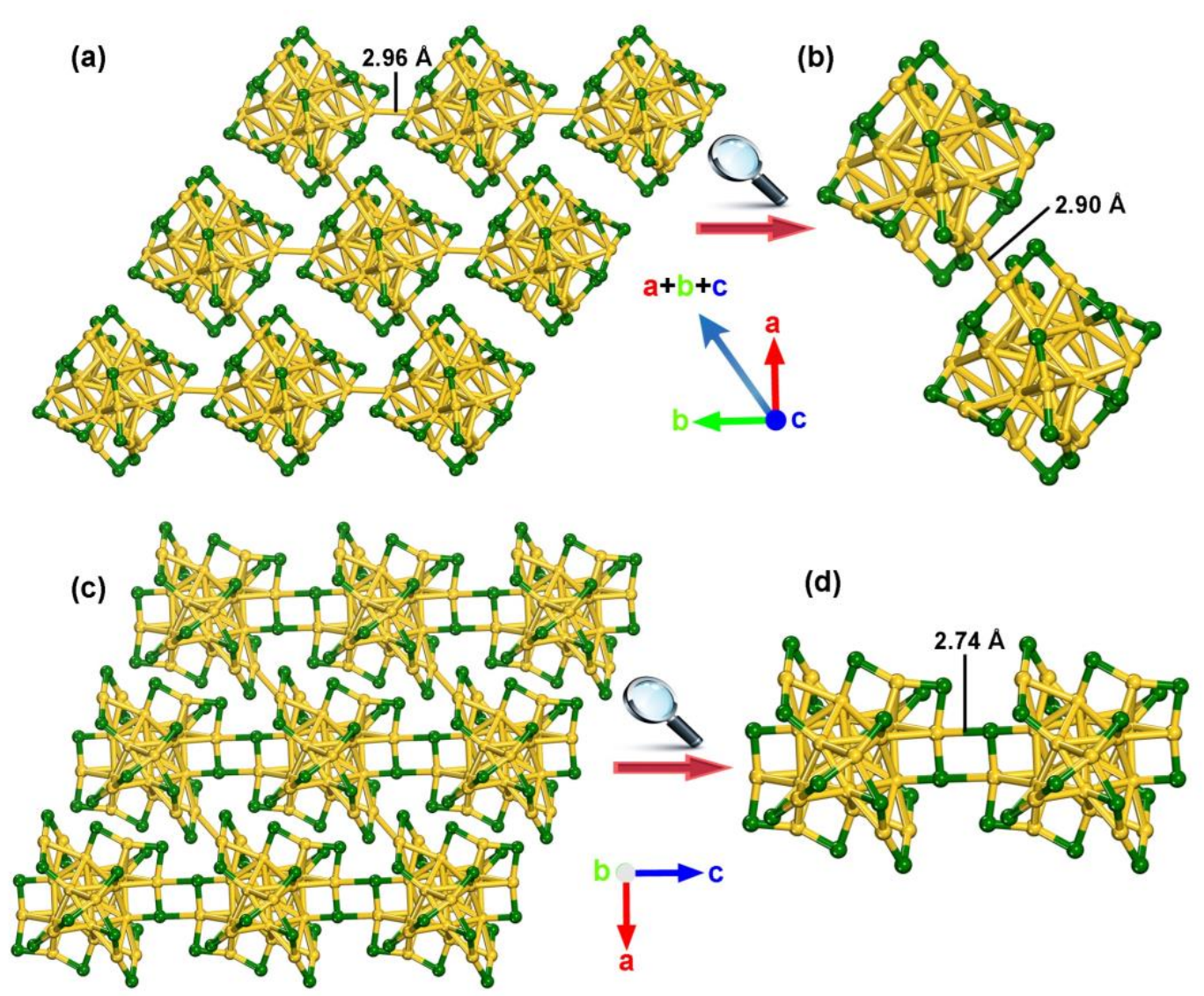

Figure 3. $\mathrm{Au}_{25}\left(\mathrm{SC}_{2} \mathrm{H}_{5}\right)_{18}$ crystal at $25 \mathrm{GPa}\left(\mathrm{C}_{2} \mathrm{H}_{5}\right.$ omitted for clarity): (a) viewed along the c-axis; (b) zoom-in on the Au-Au bond formed along the diagonal or $\mathbf{a}+\mathbf{b}+\mathbf{c}$ direction; (c) viewed along the b-axis; (d) zoom-in of the inter-staple Au-S bonds and rectangles along the c-axis.

At 50 GPa. The 3D framework of the $\mathrm{Au}_{25}\left(\mathrm{SC}_{2} \mathrm{H}_{5}\right)_{18}$ solid becomes strengthened when the pressure increases to $50 \mathrm{GPa}$ (Figure 4). In addition to the much shortened inter-cluster $\mathrm{Au}$ Au bond $(2.60 \AA)$ along the b-axis (Figure $4 a)$ and Au-S bonds $(2.60 \AA)$ along the c-axis (Figure 4e), the $\mathrm{Au}_{25}\left(\mathrm{SC}_{2} \mathrm{H}_{5}\right)_{18}$ lattice additionally forms a new inter-cluster $\mathrm{Au}-\mathrm{Au}$ bond $(2.71 \AA$ ) along the a-axis (Figure 4b). More interestingly, two new S-S bonds (2.54 $\AA$ ) are formed, flanking the Au-Au bond (2.70 $\AA$ ) along the diagonal direction (Figure 4c); put in a different way, two parallel linear S-Au-S groups from the two staple motifs fuse together 
into a three-rung ladder. One also sees that the -Au-S-Au-S- rectangle along the c-axis at $25 \mathrm{GPa}$ now deforms to a parallelogram at $50 \mathrm{GPa}$ (Figure 4e).

(a)
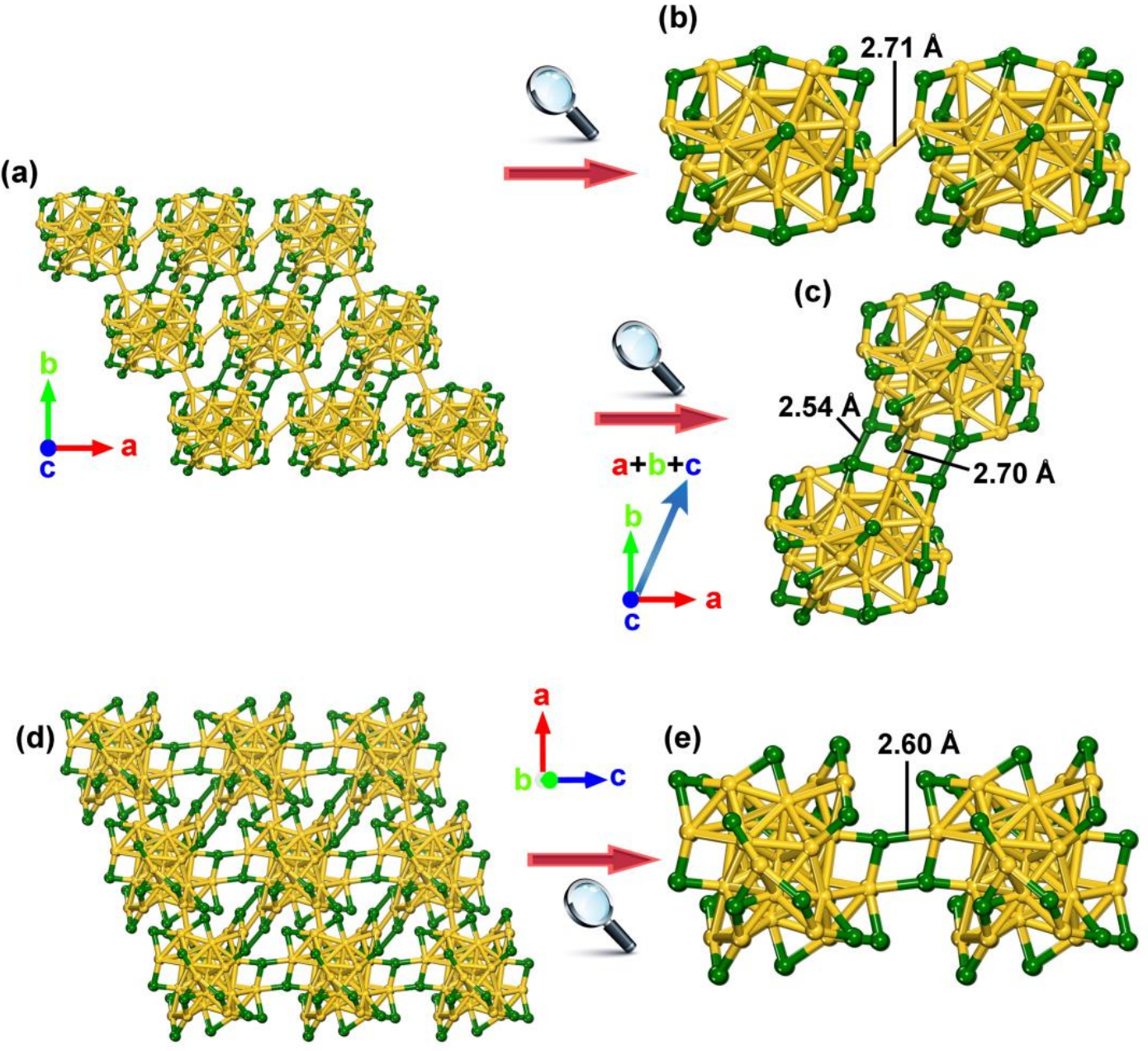

Figure 4. $\mathrm{Au}_{25}\left(\mathrm{SC}_{2} \mathrm{H}_{5}\right)_{18}$ crystal at $50 \mathrm{GPa}\left(\mathrm{C}_{2} \mathrm{H}_{5}\right.$ omitted for clarity): (a) viewed along the c-axis; (b) zoom-in view of the inter-cluster Au-Au bond formed along the a-axis; (c) zoom-in view of the inter-cluster Au-Au and S-S bonds along the diagonal $(\mathbf{a}+\mathbf{b}+\mathbf{c})$; (d) viewed along the b-axis; (e) zoom-in view of the deformation of the inter-cluster -Au-S-Au-S- ring along the c-axis.

At $80 \mathrm{GPa}$. As the pressure goes up to $80 \mathrm{GPa}$, the inter-cluster linkages are greatly enhanced (Figure 5). Not only are the three-rung ladder connection along the diagonal and the parallelogram connection along the c-axis well preserved, but a new type of three-rung 
ladder-like linkage (Figure 5a,b) and a new parallelogram connection (Figure 5c,d) are also formed along the-b axis and the a-axis, respectively.
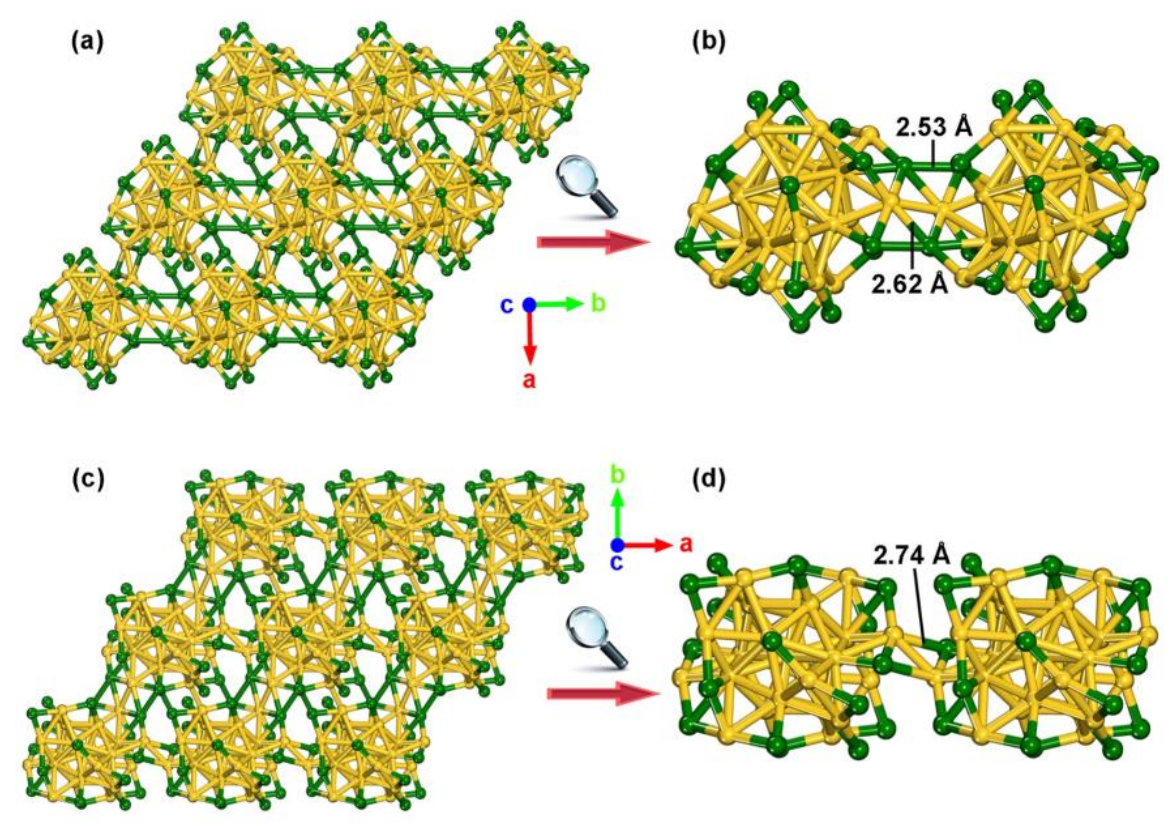

Figure 5. $\mathrm{Au}_{25}\left(\mathrm{SC}_{2} \mathrm{H}_{5}\right)_{18}$ crystal at $80 \mathrm{GPa}\left(\mathrm{C}_{2} \mathrm{H}_{5}\right.$ omitted for clarity): (a) viewed along the c-axis; (b) zoom-in view of the inter-cluster Au-S and S-S bonds along the b-axis; (c) viewed along the c-axis in a different perspective; (d) zoom-in view of the inter-cluster Au-S bonds along the a-axis.

At $110 \mathrm{GPa}$. As the pressure increases to $110 \mathrm{GPa}$, one sees the formation of more complicated inter-cluster linkages, accompanied by a great deformation of the $\mathrm{Au}_{13}$ core, in addition to the slightly changed three-rung ladder-like bond pattern (Figure 6a) and parallelogram or diamond-shaped connection (Figure 6b). Particularly, a new type of intercluster edge-sharing Au4 parallelogram emerges along the a-axis (Figure 6c). 


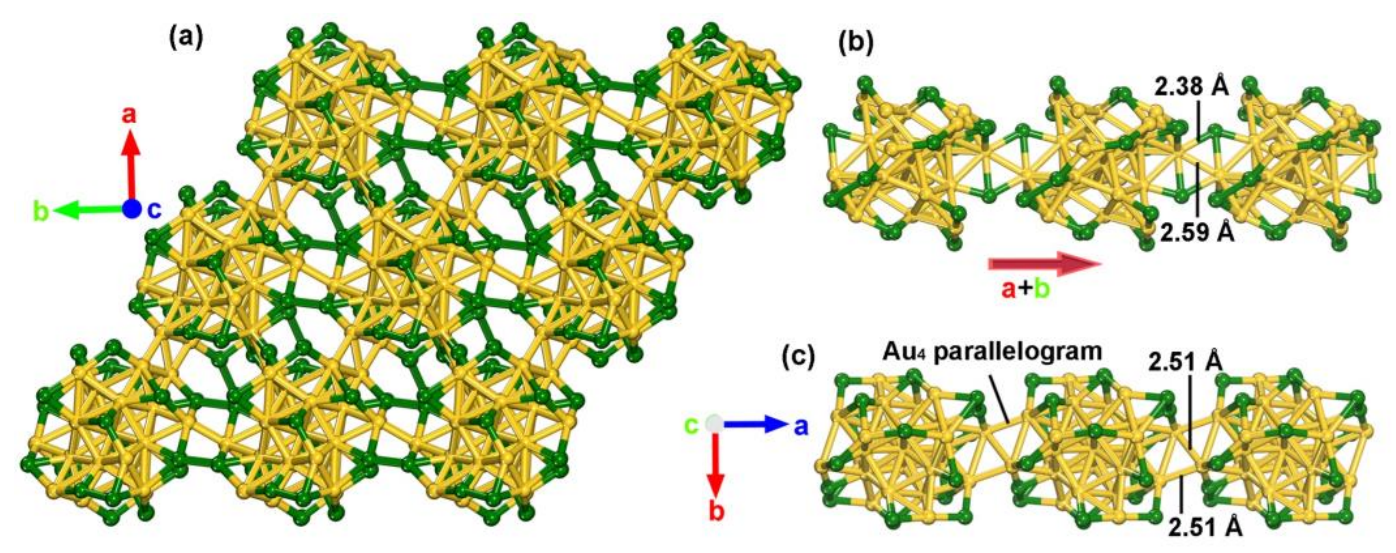

Figure 6. $\mathrm{Au}_{25}\left(\mathrm{SC}_{2} \mathrm{H}_{5}\right)_{18}$ crystal at $110 \mathrm{GPa}\left(\mathrm{C}_{2} \mathrm{H}_{5}\right.$ omitted for clarity): (a) viewed along the c-axis; (b) zoom-in view of the inter-cluster $\mathrm{Au}-\mathrm{S}$ and $\mathrm{Au}$-Au bonds along $\mathbf{a}+\mathbf{b}$ direction; (c) zoom-in view of the inter-cluster $\mathrm{Au}_{4}$ parallelogram along the a-axis.

We note that in the compressed $\mathrm{Au}_{25}\left(\mathrm{SC}_{2} \mathrm{H}_{5}\right)_{18}$ crystal, the $-\mathrm{C}_{2} \mathrm{H}_{5}$ ligands are interacting in shorter distances (Figure 7). According to our structural analysis, the shortest inter-cluster H-H distances are $1.620 \AA(10 \mathrm{GPa}), 1.633 \AA(25 \mathrm{GPa}), 1.475 \AA(50 \mathrm{GPa})$, $1.460 \AA(80 \mathrm{GPa})$, and $1.326 \AA(110 \mathrm{GPa})$; the shortest inter-cluster $\mathrm{C}-\mathrm{H}$ distances are $2.368 \AA(10 \mathrm{GPa}), 2.175 \AA(25 \mathrm{GPa}), 2.168 \AA(50 \mathrm{GPa}), 2.122 \AA$ (80 GPa), and $2.012 \AA$ (110 GPa). Based on the cutoffs of $1.58 \AA$ for $\mathrm{H}-\mathrm{H}$ and $2.03 \AA$ for C-C (Table 2), the intercluster $\mathrm{H}-\mathrm{H}$ interactions are mainly physical or of the dispersion type up to $25 \mathrm{GPa}$ (Figure 7a-c) but become chemical at $50 \mathrm{GPa}$ or higher (Figure 7d-f), while the inter-cluster C-H chemical interaction can be found only at $110 \mathrm{GPa}$ (Figure $7 \mathrm{f}$ ). In other words, $-\mathrm{C}_{2} \mathrm{H}_{5}$ ligands are interacting with each other mainly via $\mathrm{H}-\mathrm{H}$ chemical bonding at higher pressures. 
(a) $0 \mathrm{GPa}$

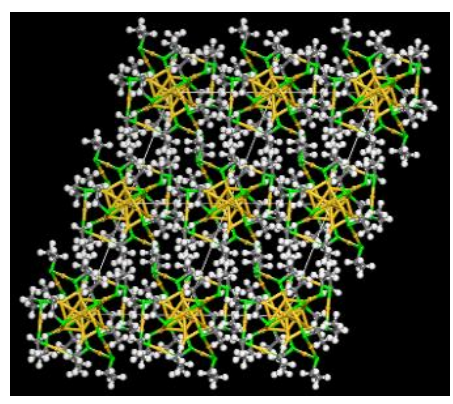

(d) $50 \mathrm{GPa}$

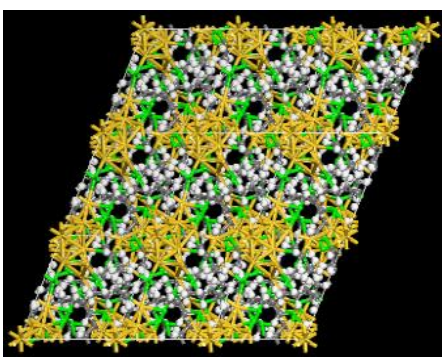

(b) $10 \mathrm{GPa}$

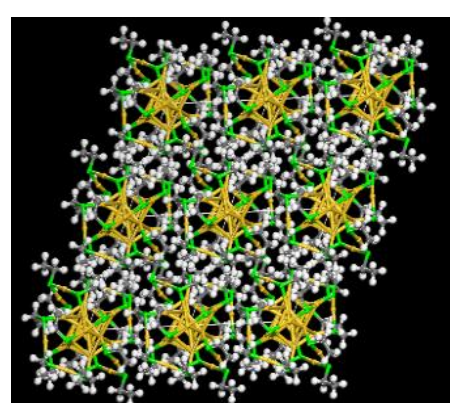

(e) $80 \mathrm{GPa}$

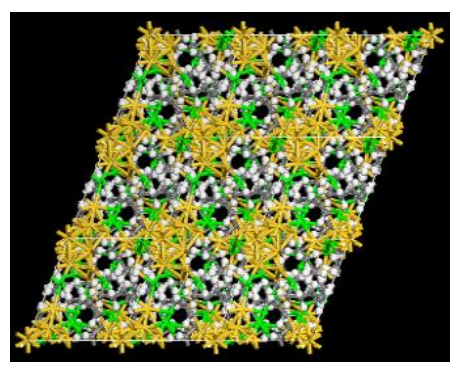

(c) $25 \mathrm{GPa}$

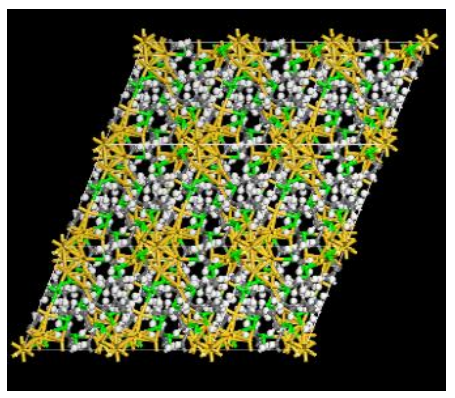

(f) $110 \mathrm{GPa}$

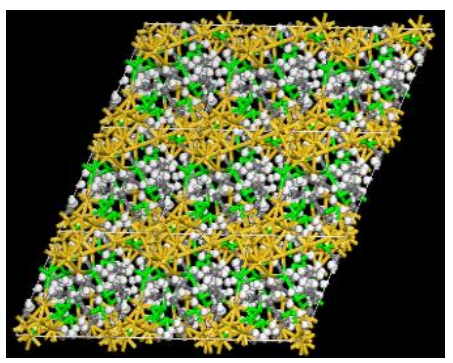

Figure 7. The packed structure of the $\mathrm{Au}_{25}\left(\mathrm{SC}_{2} \mathrm{H}_{5}\right)_{18}$ crystal at various pressures showing also the $\mathrm{C}_{2} \mathrm{H}_{5}$ groups.

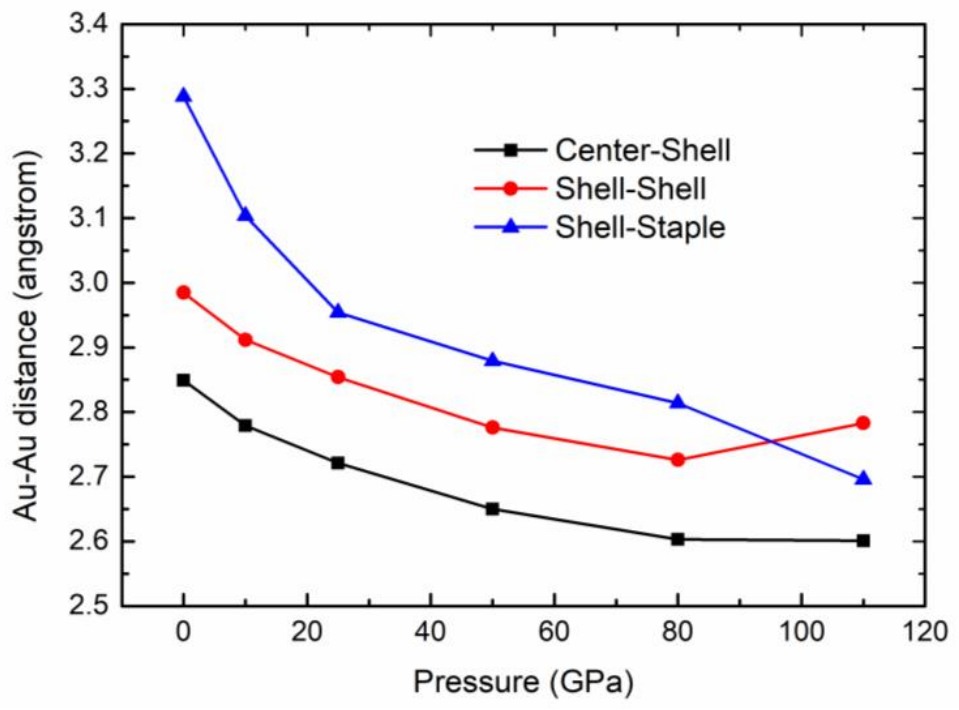

Figure 8. Relevant average $\mathrm{Au}-\mathrm{Au}$ bond distances of the ground-state and the compressed $\mathrm{Au}_{25}\left(\mathrm{SC}_{2} \mathrm{H}_{5}\right)_{18}$ cluster at different pressures. $\mathrm{Au}_{\text {center- }}-\mathrm{Au}_{\text {shell }}$ : from the central $\mathrm{Au}$ to the $12 \mathrm{Au}$ atoms at the icosahedron surface; $\mathrm{Au}_{\text {shell }}-\mathrm{Au}_{\text {shell }}$ : bonds between the $12 \mathrm{Au}$ atoms of the icosahedron surface; $\mathrm{Au}_{\text {shell- }}-\mathrm{Au}_{\text {staple: }}$ distance between staple $\mathrm{Au}$ and the icosahedron $\mathrm{Au}$ atoms. 
Intracluster change with pressure. In addition to the interesting inter-cluster bonding over a broad range of pressures, it is also of great interest to examine the structural changes to the $\mathrm{Au}_{25}\left(\mathrm{SC}_{2} \mathrm{H}_{5}\right)_{18}$ cluster itself inside the crystal during compression. Figure 8 presents the variation of key intra-cluster $\mathrm{Au}-\mathrm{Au}$ bond distances with pressure that shows an expected decreasing trend. Examining the overall cluster shape, one can see that the structural integrity of the $\mathrm{Au}_{25}\left(\mathrm{SC}_{2} \mathrm{H}_{5}\right)_{18}$ cluster (Figure 9a) is well preserved at $10 \mathrm{GPa}$ (Figure 9b), while more $\mathrm{Au}-\mathrm{Au}$ bonds are formed between staple $\mathrm{Au}$ atoms and the icosahedral $\mathrm{Au}$ atoms. Starting at $25 \mathrm{GPa}$ (Figure 9c), the S-Au-S-Au-S staple motifs become distorted, intra-staple $\mathrm{Au}-\mathrm{Au}$ bonds are formed, and some terminal S atoms of one staple become bonded with $\mathrm{Au}$ in a nearby staple. At $50 \mathrm{GPa}$, the staples become more twisted and S-S bonds begin to form between nearest staples (Figure 9d); in addition, there is bonding between $\mathrm{H}$ on $\mathrm{C}_{2} \mathrm{H}_{5}$ and the icosahedral $\mathrm{Au}$ atoms (six $\mathrm{Au}-\mathrm{H}$ bonds are formed with Au-H distance of $\sim 2.0 \AA$ A). At $80 \mathrm{GPa}$ (Figure 9e) and $110 \mathrm{GPa}$ (Figure 9f), one sees formation of more S-S bonds, Au-H bonds, and Au-S bonds.

The structural evolution of the Au13 core with pressure is shown in Figure 10. The icosahedral $\mathrm{Au}_{13}$ core in the ambient $\mathrm{Au}_{25}\left(\mathrm{SC}_{2} \mathrm{H}_{5}\right)_{18}$ crystal has an approximate Ih symmetry. With the pressure increasing, the $\mathrm{Au}_{13}$ core becomes compressed but still maintains the Ih symmetry at 10 and $25 \mathrm{GPa}$ (Figure 10b,c). However, the $\mathrm{Au}_{13}$ core becomes significantly more distorted and squashed starting at $50 \mathrm{GPa}$ (Figure 10d) and a distinct transition takes place from 80 (Figure 10e) to $110 \mathrm{Ga}$ where the $\mathrm{Au}_{13}$ core switches to an Oh-like symmetry (Figure 10f). 
(a)

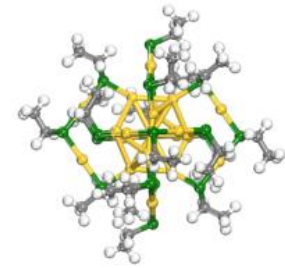

(c)
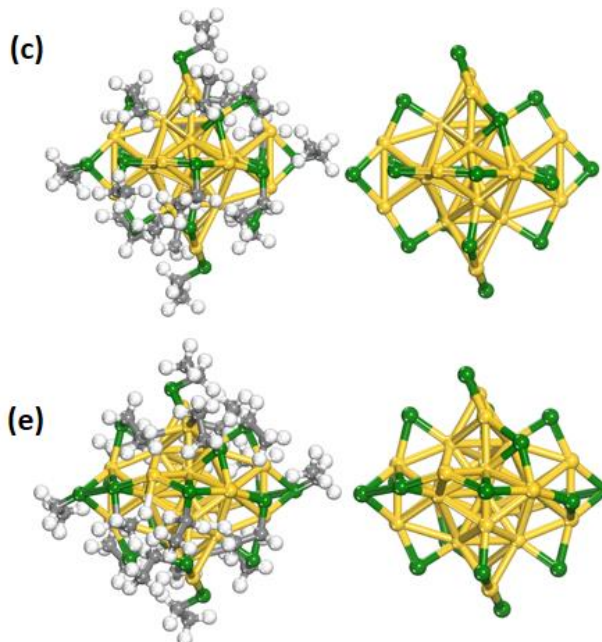

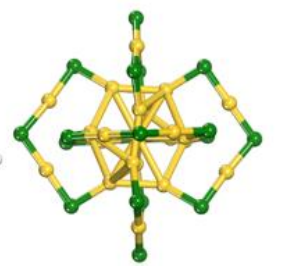

(d)

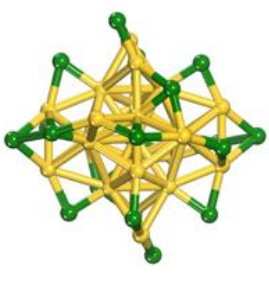

(b)

(f)
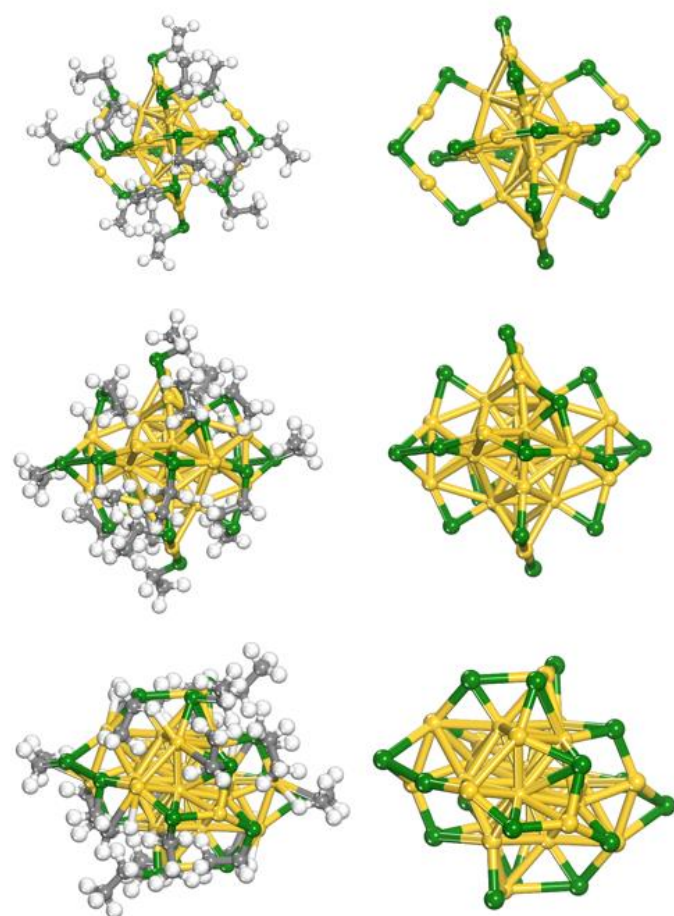

Figure 9. Structure of the $\mathrm{Au}_{25}\left(\mathrm{SC}_{2} \mathrm{H}_{5}\right)_{18}$ cluster (left) and its $\mathrm{Au}-\mathrm{S}$ framework (right) in the crystal at various pressures: (a) ambient; (b) $10 \mathrm{GPa}$; (c) $25 \mathrm{GPa}$; (d) $50 \mathrm{GPa}$; (e) $80 \mathrm{GPa}$; (f) $110 \mathrm{GPa}$.

(a) $0 \mathrm{GPa}$

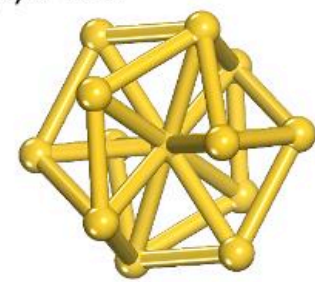

(d) $50 \mathrm{GPa}$

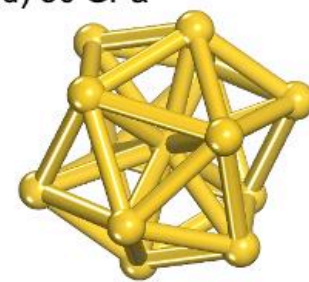

(b) $10 \mathrm{GPa}$

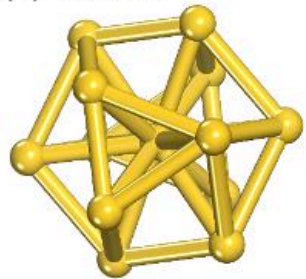

(e) $80 \mathrm{GPa}$

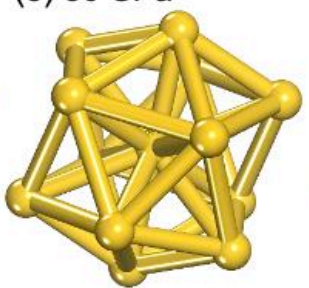

(c) $25 \mathrm{GPa}$

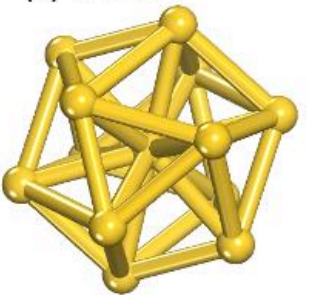

(f) $110 \mathrm{GPa}$

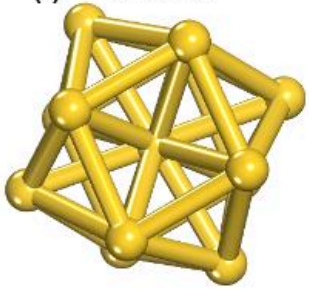

Figure 10. The structural change of the $\mathrm{Au}_{13}$ core with pressure. Note that $3.1 \AA$ is used as the cutoff for drawing a bond between two Au atoms. 

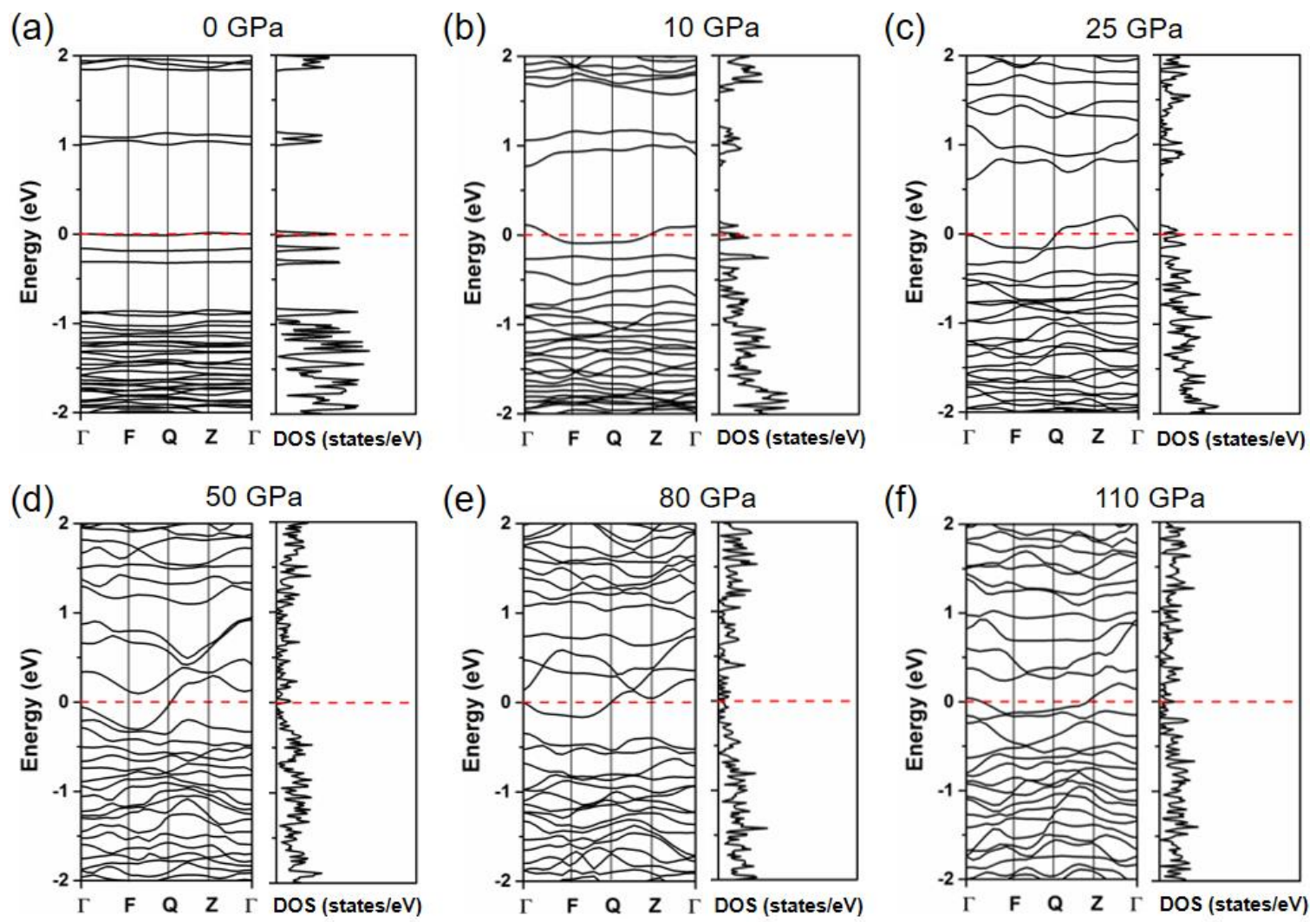

Figure 11. Band structure and density of states of $\mathrm{Au}_{25}\left(\mathrm{SC}_{2} \mathrm{H}_{5}\right)_{18}$ crystal at various pressures: (a) ambient; (b) $10 \mathrm{GPa}$; (c) $25 \mathrm{GPa}$; (d) $50 \mathrm{GPa}$; (e) $80 \mathrm{GPa}$; (f) $110 \mathrm{GPa}$. The Fermi level is set as zero and denoted by the dashed red line.

Electronic structure change with pressure. The electronic band structures and density of states for the ground state and the compressed $\mathrm{Au}_{25}\left(\mathrm{SC}_{2} \mathrm{H}_{5}\right)_{18}$ structures were also explored, which show strong structure-dependence. One can see that the $\mathrm{Au}_{25}\left(\mathrm{SC}_{2} \mathrm{H}_{5}\right)_{18}$ crystal at ambient pressure has flat and discrete energy bands, characteristic of a typical molecular crystal (Figure 11a). Starting at the pressure of $10 \mathrm{GPa}$ (Figure 11b), one sees clear band dispersion, and the band at the Fermi level becomes partially occupied, indicating a 
metallic character. When the pressure further increases (Figure 11c-f), the conduction band above the Fermi level gradually shifts downward while the valence band below Fermi level shifts upward. This leads to the broadening and delocalization of the energy states, and the bands also become more dispersed. Moreover, all the compressed $\mathrm{Au}_{25}\left(\mathrm{SC}_{2} \mathrm{H}_{5}\right)_{18}$ crystals $(10 \sim 110 \mathrm{GPa})$ are non-magnetic.

\section{Conclusions}

In summary, we explored systematically the structural and electronic properties of $\mathrm{Au}_{25}\left(\mathrm{SC}_{2} \mathrm{H}_{5}\right)_{18}$ superatomic cluster under pressure (up to $110 \mathrm{GPa}$ ). Our computations discovered that under compression, the $\mathrm{Au}_{25}\left(\mathrm{SC}_{2} \mathrm{H}_{5}\right)_{18}$ cluster will take up not a molecular but the inter-connected solid crystal, due to the formation of inter-cluster $\mathrm{Au}-\mathrm{Au}, \mathrm{Au}-\mathrm{S}$ and $\mathrm{S}-\mathrm{S}$ bonds. We also observed the formation of intra-cluster $\mathrm{Au}-\mathrm{Au}, \mathrm{Au}-\mathrm{S}, \mathrm{S}-\mathrm{S}$ and $\mathrm{Au}-\mathrm{H}$ bonds. At atmospheric pressure, the $\mathrm{Au}_{25}\left(\mathrm{SC}_{2} \mathrm{H}_{5}\right)_{18}$ cluster has an unpaired valence electron; upon compression, the cluster interacts closely to pair the valence electron and the magnetic moment vanishes. All the compressed clusters are predicted to be metallic. Our DFT findings represent a significant step toward understanding the high-pressure behavior of superatomic gold nanoclusters. We hope that this work will greatly stimulate the highpressure experiments in future on the structure, bonding and conductivity measurements of atomically precise metal nanoclusters.

\section{Acknowledgments}

This work was sponsored by the University of California Riverside. This research used resources of the National Energy Research Scientific Computing Center, a DOE Office of 
Science User Facility supported by the Office of Science of the U.S. Department of Energy under contract no. DE-AC02-05CH11231.

\section{Supporting Information Available.}

Coordinates of the optimized atomic positions in the $\mathrm{Au}_{25}\left(\mathrm{SC}_{2} \mathrm{H}_{5}\right)_{18}$ crystal at various pressures

\section{References}

(1) Duan, D. F.; Liu, Y. X.; Tian, F. B.; Li, D.; Huang, X. L.; Zhao, Z. L.; Yu, H. Y.; Liu, B. B.; Tian, W. J.; Cui, T. Pressure-induced metallization of dense $\left(\mathrm{H}_{2} \mathrm{~S}\right)_{2} \mathrm{H}_{2}$ with high-Tc superconductivity. Sci. Rep. 2014, 4, 6968.

(2) Drozdov, A. P.; Kong, P. P.; Minkov, V. S.; Besedin, S. P.; Kuzovnikov, M. A.; Mozaffari, S.; Balicas, L.; Balakirev, F. F.; Graf, D. E.; Prakapenka, V. B.; Greenberg, E.; Knyazev, D. A.; Tkacz, M.; Eremets, M. I. Superconductivity at 250 K in lanthanum hydride under high pressures. Nature 2019, 569, 528-531.

(3) Matsuoka, T.; Shimizu, K. Direct observation of a pressure-induced metal-tosemiconductor transition in lithium. Nature 2009, 458, 186-189.

(4) Babaev, E.; Sudbo, A.; Ashcroft, N. W. A superconductor to superfluid phase transition in liquid metallic hydrogen. Nature 2004, 431, 666-668.

(5) Pickard, C. J.; Needs, R. J. High-pressure phases of silane. Phys. Rev. Lett. 2006, 97, 045504.

(6) Drozdov, A. P.; Eremets, M. I.; Troyan, I. A.; Ksenofontov, V.; Shylin, S. I. Conventional superconductivity at 203 kelvin at high pressures in the sulfur hydride system. Nature 2015, 525, 73-76.

(7) Miao, M. S.; Hoffmann, R. High Pressure Electrides: A Predictive Chemical and Physical Theory. Acc. Chem. Res. 2014, 47, 1311-1317.

(8) Naumov, II; Hemley, R. J.; Hoffmann, R.; Ashcroft, N. W. Chemical bonding in hydrogen and lithium under pressure. J. Chem. Phys. 2015, 143, 064702. 
(9) Miao, M. S.; Hoffmann, R.; Botana, J.; Naumov, II; Hemley, R. J. Quasimolecules in Compressed Lithium. Angew.Chem.Int. Ed. 2017, 56, 972-975.

(10) Prasad, D.; Ashcroft, N. W.; Hoffmann, R. Evolving Structural Diversity and Metallicity in Compressed Lithium Azide. J. Phys. Chem. C 2013, 117, 20838-20846.

(11) Behler, J.; Martonak, R.; Donadio, D.; Parrinello, M. Metadynamics simulations of the high-pressure phases of silicon employing a high-dimensional neural network potential. Phys. Rev. Lett. 2008, 100, 185501.

(12) AlKaabi, K.; Prasad, D.; Kroll, P.; Ashcroft, N. W.; Hoffmann, R. Silicon Monoxide at $1 \mathrm{~atm}$ and Elevated Pressures: Crystalline or Amorphous? J. Am. Chem. Soc. 2014, 136, 3410-3423.

(13) Kuwayama, Y.; Hirose, K.; Sata, N.; Ohishi, Y. The pyrite-type high-pressure form of silica. Science 2005, 309, 923-925.

(14) Wang, Y. C.; Ma, Y. M. Perspective: Crystal structure prediction at high pressures. $J$. Chem. Phys. 2014, 140, 040901.

(15) Zhang, L. J.; Wang, Y. C.; Lv, J.; Ma, Y. M. Materials discovery at high pressures. Nat. Rev. Mater. 2017, 2, 17005.

(16) Jin, R.; Zeng, C.; Zhou, M.; Chen, Y. Atomically Precise Colloidal Metal Nanoclusters and Nanoparticles: Fundamentals and Opportunities. Chem. Rev. 2016, 116, 10346-10413. (17) Chakraborty, I.; Pradeep, T. Atomically Precise Clusters of Noble Metals: Emerging Link between Atoms and Nanoparticles. Chem. Rev. 2017, 117, 8208-8271.

(18) Du, Y. X.; Sheng, H. T.; Astruc, D.; Zhu, M. Z. Atomically Precise Noble Metal Nanoclusters as Efficient Catalysts: A Bridge between Structure and Properties. Chem. Rev. 2020, 120, 526-622.

(19) Kang, X.; Li, Y. W.; Zhu, M. Z.; Jin, R. C. Atomically precise alloy nanoclusters: syntheses, structures, and properties. Chem. Soc. Rev. 2020, 49, 6443-6514.

(20) Li, G.; Jin, R. C. Atomically Precise Gold Nanoclusters as New Model Catalysts. Acc. Chem. Res. 2013, 46, 1749-1758.

(21) Tang, Q.; Hu, G. X.; Fung, V.; Jiang, D. E. Insights into Interfaces, Stability, Electronic Properties, and Catalytic Activities of Atomically Precise Metal Nanoclusters from First Principles. Acc. Chem. Res. 2018, 51, 2793-2802. 
(22) Chai, O. J. H.; Liu, Z.; Chen, T.; Xie, J. Engineering ultrasmall metal nanoclusters for photocatalytic and electrocatalytic applications. Nanoscale 2019, 11, 20437-20448.

(23) Jin, R. C.; Li, G.; Sharma, S.; Li, Y. W.; Du, X. S. Toward Active-Site Tailoring in Heterogeneous Catalysis by Atomically Precise Metal Nanoclusters with Crystallographic Structures. Chem. Rev. 2021, 121, 567-648.

(24) Tao, Y.; Li, M. Q.; Ren, J. S.; Qu, X. G. Metal nanoclusters: novel probes for diagnostic and therapeutic applications. Chem. Soc. Rev. 2015, 44, 8636-8663.

(25) Loynachan, C. N.; Soleimany, A. P.; Dudani, J. S.; Lin, Y. Y.; Najer, A.; Bekdemir, A.; Chen, Q.; Bhatia, S. N.; Stevens, M. M. Renal clearable catalytic gold nanoclusters for in vivo disease monitoring. Nat. Nanotech. 2019, 14, 883-890.

(26) Srinivasulu, Y. G.; Yao, Q. F.; Goswami, N.; Xie, J. P. Interfacial engineering of gold nanoclusters for biomedical applications. Mater. Horiz. 2020, 7, 2596-2618.

(27) Zheng, Y. K.; Wu, J. B.; Jiang, H.; Wang, X. M. Gold nanoclusters for theranostic applications. Coord. Chem. Rev. 2021, 431, 213689.

(28) Goswami, N.; Lin, F. X.; Liu, Y. B.; Leong, D. T.; Xie, J. P. Highly Luminescent Thiolated Gold Nanoclusters Impregnated in Nanogel. Chem. Mater. 2016, 28, 4009-4016. (29) Xu, M. M.; Jia, T. T.; Li, B. J.; Ma, W.; Chen, X. Y.; Zhao, X. L.; Zang, S. Q. Tuning the properties of atomically precise gold nanoclusters for biolabeling and drug delivery. Chem. Comm. 2020, 56, 8766-8769.

(30) Li, Q.; Zhou, M.; So, W. Y.; Huang, J. C.; Li, M. X.; Kauffman, D. R.; Cotlet, M.; Higaki, T.; Peteanu, L. A.; Shao, Z. Z.; Jin, R. A Mono-cuboctahedral Series of Gold Nanoclusters: Photoluminescence Origin, Large Enhancement, Wide Tunability, and Structure-Property Correlation. J. Am. Chem. Soc. 2019, 141, 5314-5325.

(31) Dong, J. W.; Gan, Z. B.; Gu, W. M.; You, Q.; Zhao, Y.; Zha, J.; Li, J.; Deng, H. T.; Yan, N.; Wu, Z. K. Synthesizing Photoluminescent $\mathrm{Au}_{28}\left(\mathrm{SCH}_{2} \mathrm{Ph}-{ }^{-} \mathrm{Bu}\right)_{22}$ Nanoclusters with Structural Features by Using A Combined Method. Angew. Chem. 2021, 133, 18076-18080. (32) Malola, S.; Lehtovaara, L.; Enkovaara, J.; Hakkinen, H. Birth of the Localized Surface Plasmon Resonance in Mono layer-Protected Gold Nanoclusters. ACS Nano 2013, 7, 10263-10270. 
(33) Gieseking, R. L. M.; Ashwell, A. P.; Ratner, M. A.; Schatz, G. C. Analytical Approaches To Identify Plasmon-like Excited States in Bare and Ligand-Protected Metal Nanoclusters. J. Phys. Chem. C 2020, 124, 3260-3269.

(34) Reato, M.; Dainese, T.; Antonello, S.; Maran, F. Electron Transfer in Films of Atomically Precise Gold Nanoclusters. Chem. Mater. 2021, 33, 4177-4187.

(35) Yoon, B.; Luedtke, W. D.; Barnett, R. N.; Gao, J. P.; Desireddy, A.; Conn, B. E.; Bigioni, T.; Landman, U. Hydrogen-bonded structure and mechanical chiral response of a silver nanoparticle superlattice. Nat. Mater. 2014, 13, 807-811.

(36) Li, Q.; Mosquera, M. A.; Jones, L. O.; Parakh, A.; Chai, J. S.; Jin, R. C.; Schatz, G. C.; Gu, X. W. Pressure-Induced Optical Transitions in Metal Nanoclusters. ACS Nano 2020, 14, 11888-11896.

(37) Sun, Q. Q.; Li, Q.; Li, H. Y.; Zhang, M. M.; Sun, M. E.; Li, S.; Quan, Z. W.; Zang, S. Q. Thermochromism and piezochromism of an atomically precise high-nuclearity silver sulfide nanocluster. Chem. Commun. 2021, 57, 2372-2375.

(38) Kang, X.; Chong, H. B.; Zhu, M. Z. Au25(SR) 18 : the captain of the great nanocluster ship. Nanoscale 2018, 10, 10758-10834.

(39) Dainese, T.; Antonello, S.; Gascon, J. A.; Pan, F. F.; Perera, N. V.; Ruzzi, M.; Venzo, A.; Zoleo, A.; Rissanen, K.; Maran, F. $\mathrm{Au}_{25}(\mathrm{SEt})_{18}$, a Nearly Naked Thiolate-Protected $\mathrm{Au}_{25}$ Cluster: Structural Analysis by Single Crystal X-ray Crystallography and Electron Nuclear Double Resonance. ACS Nano 2014, 8, 3904-3912.

(40) Kresse, G.; Furthmuller, J. Efficient Iterative Schemes for ab Initio Total-Energy Calculations Using a Plane-Wave Basis Set. Phys. Rev. B 1996, 54, 11169-11186.

(41) Blochl, P. E. Projector Augmented-Wave Method. Phys. Rev. B 1994, 50, 1795317979.

(42) Perdew, J. P.; Burke, K.; Ernzerhof, M. Generalized gradient approximation made simple. Phys. Rev. Lett. 1996, 77, 3865-3868.

(43) Grimme, S.; Antony, J.; Ehrlich, S.; Krieg, H. A Consistent and Accurate ab Initio Parametrization of Density Functional Dispersion Correction (DFT-D) for the 94 Elements H-Pu. J. Chem. Phys. 2010, 132, 154104. 
(44) Walter, M.; Akola, J.; Lopez-Acevedo, O.; Jadzinsky, P. D.; Calero, G.; Ackerson, C. J.; Whetten, R. L.; Gronbeck, H.; Hakkinen, H. A unified view of ligand-protected gold clusters as superatom complexes. PNAS 2008, 105, 9157-9162.

(45) De Nardi, M.; Antonello, S.; Jiang, D. E.; Pan, F. F.; Rissanen, K.; Ruzzi, M.; Venzo, A.; Zoleo, A.; Maran, F. Gold Nanowired: A Linear (Au25)n Polymer from Au25 Molecular Clusters. ACS Nano 2014, 8, 8505-8512. 


\section{TOC Graphic}

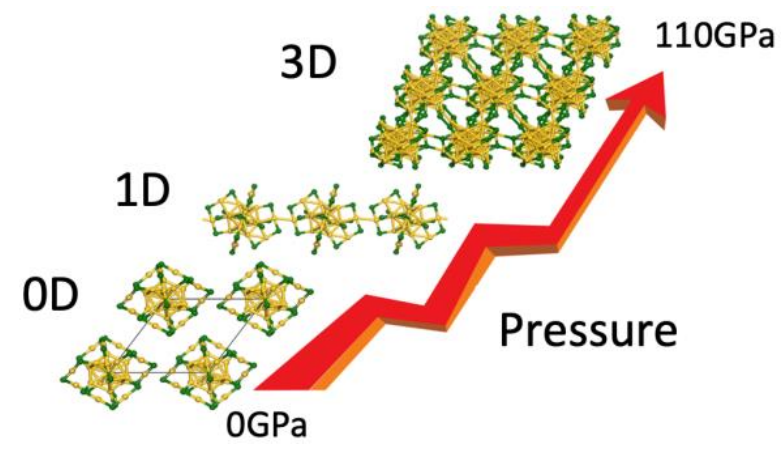




\title{
Supporting Information
}

\section{Superatomic $\mathrm{Au}_{25}\left(\mathrm{SC}_{2} \mathrm{H}_{5}\right)_{18}$ Nanocluster under Pressure}

\author{
Qing Tang ${ }^{\dagger}$, Fuhua $\mathrm{Li}^{\dagger}$ and De-en Jiang** \\ ${ }^{\dagger}$ School of Chemistry and Chemical Engineering, Chongqing Key Laboratory of Theoretical \\ and Computational Chemistry, Chongqing University, Chongqing 401331, China \\ ${ }^{\sharp}$ Department of Chemistry, University of California, Riverside, California 92521, United
} States

* To whom correspondence should be addressed. E-mail: djiang@ucr.edu

The atomic fractional coordinates of $\mathrm{Au}_{25}(\mathrm{SEt})_{18}$ crystal $\left(\mathrm{Et}=\mathrm{C}_{2} \mathrm{H}_{5}\right)$ under various pressures in VASP POSCAR format.

(1) Ambient pressure

1.0

\begin{tabular}{|c|c|c|c|c|c|}
\hline \multicolumn{4}{|c|}{13.7727003098} & 0.0000000000 & 0.0000000000 \\
\hline \multicolumn{4}{|c|}{-6.7940696206} & 12.1108517098 & 0.0000000000 \\
\hline \multicolumn{4}{|c|}{-2.7986792748} & -5.6007811356 & 12.6915297284 \\
\hline $\mathrm{C}$ & $\mathrm{H}$ & $\mathrm{S}$ & $\mathrm{Au}$ & & \\
\hline 36 & 90 & 18 & 25 & & \\
\hline
\end{tabular}

$\begin{array}{lll}0.107350008 & 0.371060008 & 0.383320008 \\ 0.892649991 & 0.628939953 & 0.616679994 \\ 0.165639972 & 0.480289945 & 0.485529963 \\ 0.834360005 & 0.519710000 & 0.514469964 \\ 0.481509975 & 0.307899997 & 0.524299966 \\ 0.518489940 & 0.692099966 & 0.475699998 \\ 0.554350004 & 0.260229985 & 0.558619950 \\ 0.445649965 & 0.739770018 & 0.441380014\end{array}$




$\begin{array}{lll}0.364349974 & 0.868580002 & 0.141909998 \\ 0.635650048 & 0.131420020 & 0.858089966 \\ 0.456089941 & 0.880819904 & 0.232120001 \\ 0.543910043 & 0.119180030 & 0.767879944 \\ 0.160929989 & 0.003559988 & 0.437489957 \\ 0.839070020 & 0.996439955 & 0.562510007 \\ 0.103379955 & 0.870559914 & 0.375919967 \\ 0.896619954 & 0.129440019 & 0.624079998 \\ 0.209509965 & 0.877009959 & 0.671879960 \\ 0.790490016 & 0.122989997 & 0.328119967 \\ 0.241209968 & 0.789529968 & 0.627629959 \\ 0.758790000 & 0.210470014 & 0.372370006 \\ 0.984149991 & 0.470209950 & 0.778439956 \\ 0.015849959 & 0.529790004 & 0.221559989 \\ 0.040879959 & 0.453149969 & 0.699819926 \\ 0.959119929 & 0.546849937 & 0.300180001 \\ 0.701379979 & 0.496749959 & 0.987600010 \\ 0.298619982 & 0.503250012 & 0.012399971 \\ 0.669499902 & 0.471799968 & 0.871539963 \\ 0.330499998 & 0.528200025 & 0.128459983 \\ 0.676140014 & 0.635849980 & 0.243329997 \\ 0.323859971 & 0.364149974 & 0.756669948 \\ 0.728070018 & 0.647039980 & 0.353489981 \\ 0.271929941 & 0.352959946 & 0.646509946 \\ 0.447719939 & 0.726209942 & 0.856059990 \\ 0.552279988 & 0.273789997 & 0.143939965 \\ 0.495749951 & 0.854109928 & 0.925949955 \\ 0.504250003 & 0.145889993 & 0.074050004 \\ 0.017289991 & 0.344240006 & 0.335960006 \\ 0.982710001 & 0.655759957 & 0.664039959 \\ 0.097479983 & 0.292509986 & 0.396710003 \\ 0.902520011 & 0.707489960 & 0.603289924 \\ 0.168359965 & 0.555659981 & 0.470859989 \\ 0.831640011 & 0.444339982 & 0.529139975 \\ 0.258739999 & 0.512379992 & 0.529189982 \\ 0.741259942 & 0.487619971 & 0.470809982 \\ 0.113969977 & 0.457459963 & 0.536130001 \\ 0.886030016 & 0.542540000 & 0.463869963 \\ 0.524999930 & 0.402969978 & 0.577189974 \\ 0.475000004 & 0.597030024 & 0.422809990 \\ 0.390130000 & 0.254590005 & 0.523280018 \\ 0.609869922 & 0.745409918 & 0.476719946 \\ 0.510369987 & 0.164749998 & 0.506910019 \\ 0.489629942 & 0.835249994 & 0.493089945\end{array}$




$\begin{array}{lll}0.563339998 & 0.267549963 & 0.639629966 \\ 0.436659943 & 0.732449963 & 0.360369961 \\ 0.645409952 & 0.313099990 & 0.558529967 \\ 0.354589954 & 0.686899973 & 0.441469997 \\ 0.305949949 & 0.775409912 & 0.081139994 \\ 0.694050024 & 0.224589983 & 0.918859952 \\ 0.406899929 & 0.929019899 & 0.103859992 \\ 0.593099986 & 0.070979999 & 0.896139916 \\ 0.513669995 & 0.857540011 & 0.202869981 \\ 0.486329966 & 0.142459974 & 0.797129946 \\ 0.411399961 & 0.819999964 & 0.269399984 \\ 0.588600054 & 0.180000019 & 0.730599981 \\ 0.514039929 & 0.973749937 & 0.293159974 \\ 0.485960034 & 0.026250013 & 0.706840046 \\ 0.255210000 & 0.057859990 & 0.444609980 \\ 0.744789914 & 0.942139953 & 0.555389984 \\ 0.159759992 & 0.021949994 & 0.517779994 \\ 0.840239959 & 0.978049988 & 0.482219970 \\ 0.098329954 & 0.851270003 & 0.294149978 \\ 0.901669971 & 0.148729971 & 0.705849968 \\ 0.011509944 & 0.815439928 & 0.373749999 \\ 0.988489966 & 0.184559993 & 0.626250003 \\ 0.157379934 & 0.842349962 & 0.413320008 \\ 0.842620045 & 0.157649971 & 0.586679956 \\ 0.112379940 & 0.836139912 & 0.638189934 \\ 0.887619969 & 0.163860022 & 0.361810031 \\ 0.255449965 & 0.958310003 & 0.655539980 \\ 0.744549968 & 0.041689979 & 0.344459984 \\ 0.218479967 & 0.764269988 & 0.542039965 \\ 0.781519956 & 0.235729975 & 0.457959999 \\ 0.191319955 & 0.706549980 & 0.640619970 \\ 0.808679969 & 0.293449983 & 0.359379995 \\ 0.337859955 & 0.828909960 & 0.664839927 \\ 0.662140026 & 0.171089995 & 0.335160000 \\ 0.945159937 & 0.392839991 & 0.800899924 \\ 0.054840005 & 0.607159955 & 0.199100003 \\ 0.913139978 & 0.482779987 & 0.747649983 \\ 0.086860009 & 0.517220006 & 0.252349963 \\ 0.971740009 & 0.373930002 & 0.626110012 \\ 0.028259959 & 0.626069980 & 0.373889952 \\ 0.110249993 & 0.438489993 & 0.730589987 \\ 0.889750006 & 0.561509939 & 0.269409996 \\ 0.083059974 & 0.532989953 & 0.681049985 \\ 0.916939949 & 0.467010010 & 0.318949979\end{array}$




$\begin{array}{lll}0.698289992 & 0.421329996 & 0.002940000 \\ 0.301709973 & 0.578669993 & 0.997059936 \\ 0.638169972 & 0.510129947 & 0.016389999 \\ 0.361829975 & 0.489870004 & 0.983609939 \\ 0.577519983 & 0.389669979 & 0.826079978 \\ 0.422479967 & 0.610329975 & 0.173919968 \\ 0.732049919 & 0.457939968 & 0.842209934 \\ 0.267949992 & 0.542060017 & 0.157789992 \\ 0.673189952 & 0.547589984 & 0.856729961 \\ 0.326809993 & 0.452409983 & 0.143270013 \\ 0.580979958 & 0.559409965 & 0.202900001 \\ 0.419019949 & 0.440589998 & 0.797099964 \\ 0.726139990 & 0.622119983 & 0.195800003 \\ 0.273859968 & 0.377879980 & 0.804199961 \\ 0.720679985 & 0.563019948 & 0.348280008 \\ 0.279319964 & 0.436979996 & 0.651719957 \\ 0.679670016 & 0.660570068 & 0.402889992 \\ 0.320330014 & 0.339429972 & 0.597110010 \\ 0.823580011 & 0.722919960 & 0.394379982 \\ 0.176419971 & 0.277080001 & 0.605620020 \\ 0.424579972 & 0.711569968 & 0.772209960 \\ 0.575420003 & 0.288429966 & 0.227789985 \\ 0.366340007 & 0.659710000 & 0.864549974 \\ 0.633659964 & 0.340289987 & 0.135449999 \\ 0.429829993 & 0.875370044 & 0.901909964 \\ 0.570170007 & 0.124629973 & 0.098089990 \\ 0.580699947 & 0.918669934 & 0.920829965 \\ 0.419299997 & 0.081330005 & 0.079169990 \\ 0.514989954 & 0.866909951 & 0.009089999 \\ 0.485010005 & 0.133090012 & 0.990909966 \\ 0.194379964 & 0.404119965 & 0.298799989 \\ 0.805619998 & 0.595880007 & 0.701199994 \\ 0.470209979 & 0.308739965 & 0.392839972 \\ 0.529790041 & 0.691259981 & 0.607159954 \\ 0.261299986 & 0.897889954 & 0.186819995 \\ 0.738699984 & 0.102110039 & 0.813179950 \\ 0.090220005 & 0.070270006 & 0.381700009 \\ 0.909779994 & 0.929729986 & 0.618299955 \\ 0.261290016 & 0.935010027 & 0.816239982 \\ 0.738709999 & 0.064989980 & 0.183759983 \\ 0.097079976 & 0.601540031 & 0.902679951 \\ 0.902920017 & 0.398459932 & 0.097320014 \\ 0.852219992 & 0.630469960 & 0.077179994 \\ 0.147780000 & 0.369530040 & 0.922819966\end{array}$




$\begin{array}{lll}0.679139919 & 0.769190005 & 0.241260007 \\ 0.320860005 & 0.230809987 & 0.758739976 \\ 0.553659934 & 0.683029947 & 0.881729973 \\ 0.446339996 & 0.316969968 & 0.118269972 \\ 0.856249969 & 0.000039997 & 0.120969996 \\ 0.143749979 & 0.999959952 & 0.879029950 \\ 0.135249964 & 0.901459959 & 0.046699997 \\ 0.864749964 & 0.098540008 & 0.953299976 \\ 0.106779993 & 0.064179996 & 0.217030000 \\ 0.893219985 & 0.935819930 & 0.782970002 \\ 0.067979987 & 0.226189992 & 0.139180002 \\ 0.932019976 & 0.773809995 & 0.860819972 \\ 0.255469997 & 0.162199994 & 0.110509998 \\ 0.744529895 & 0.837800019 & 0.889489948 \\ 0.870199952 & 0.799619947 & 0.051649996 \\ 0.129800002 & 0.200380011 & 0.948349959 \\ 0.884540011 & 0.920189994 & 0.304749985 \\ 0.115459949 & 0.079810008 & 0.695249979 \\ 0.363079988 & 0.104599995 & 0.282769991 \\ 0.636919959 & 0.895399961 & 0.717229936 \\ 0.168649955 & 0.767329962 & 0.857640013 \\ 0.831349942 & 0.232670010 & 0.142359970 \\ 0.329620003 & 0.353269981 & 0.346779974 \\ 0.670379922 & 0.646729965 & 0.653219953 \\ 0.978349966 & 0.623749948 & 0.990769975 \\ 0.021650005 & 0.376250028 & 0.009230018 \\ 0.622039948 & 0.732099954 & 0.062530003 \\ 0.377960003 & 0.267899982 & 0.937469989 \\ 0.000000000 & 0.000000000 & 0.000000000 \\ & & \end{array}$

(2) At $10 \mathrm{GPa}$ 1.0

\begin{tabular}{|c|c|c|c|c|}
\hline \multicolumn{3}{|c|}{12.3954000473} & 0.0000000000 & 0.0000000000 \\
\hline \multicolumn{3}{|c|}{-6.1146820689} & 10.8998011390 & 0.0000000000 \\
\hline \multicolumn{3}{|c|}{-2.5188093293} & -5.0406989836 & 11.4223676043 \\
\hline $\mathrm{C}$ & $\mathrm{H}$ & $\mathrm{Au}$ & & \\
\hline 36 & $90 \quad 18$ & 25 & & \\
\hline & & & & \\
\hline & .091810007 & & 0.335890017 & 0.381210022 \\
\hline & 908190036 & & 0.664110012 & 0.618789975 \\
\hline & .094630012 & & 0.448350035 & 0.460400014 \\
\hline & 905370038 & & 0.551649992 & 0.539600025 \\
\hline & .541170027 & & 0.295120021 & 0.560150035 \\
\hline & 458829985 & & 0.704880006 & 0.439850004 \\
\hline
\end{tabular}




$\begin{array}{lll}0.652530026 & 0.275700022 & 0.593020057 \\ 0.347469976 & 0.724300046 & 0.406980024 \\ 0.382600026 & 0.830980041 & 0.185260010 \\ 0.617389993 & 0.169019985 & 0.814740029 \\ 0.501840022 & 0.912460052 & 0.299430030 \\ 0.498160018 & 0.087540016 & 0.700570051 \\ 0.218009985 & 0.000459997 & 0.451270016 \\ 0.781989996 & 0.999539986 & 0.548730023 \\ 0.118510010 & 0.851289968 & 0.392710019 \\ 0.881490025 & 0.148710013 & 0.607290062 \\ 0.208529980 & 0.862770079 & 0.642100016 \\ 0.791469981 & 0.137230002 & 0.357900023 \\ 0.224300048 & 0.749500055 & 0.605409993 \\ 0.775699968 & 0.250499996 & 0.394590004 \\ 0.997720083 & 0.470600035 & 0.774050037 \\ 0.002279986 & 0.529399992 & 0.225950002 \\ 0.066350008 & 0.451130005 & 0.694160008 \\ 0.933650024 & 0.548870002 & 0.305839989 \\ 0.665850014 & 0.478600036 & 0.972230074 \\ 0.334149982 & 0.521399964 & 0.027770002 \\ 0.653229994 & 0.461010052 & 0.848540024 \\ 0.346769976 & 0.538990019 & 0.151460015 \\ 0.662250029 & 0.625540051 & 0.266650012 \\ 0.337749994 & 0.374460019 & 0.733350027 \\ 0.720059967 & 0.612120013 & 0.373460018 \\ 0.279939995 & 0.387879991 & 0.626540021 \\ 0.425599992 & 0.729619984 & 0.852509977 \\ 0.574400011 & 0.270380014 & 0.147489999 \\ 0.498790033 & 0.877890039 & 0.923390028 \\ 0.501209949 & 0.122109996 & 0.076600003 \\ 0.996510016 & 0.267110004 & 0.306349999 \\ 0.003490006 & 0.732890045 & 0.693650040 \\ 0.109940008 & 0.277220017 & 0.423700013 \\ 0.890060049 & 0.722780007 & 0.576300067 \\ 0.080699985 & 0.504250007 & 0.412150005 \\ 0.919299970 & 0.495750000 & 0.587849992 \\ 0.190000014 & 0.517200030 & 0.534660023 \\ 0.809999970 & 0.482800018 & 0.465340016 \\ 0.013880004 & 0.411430001 & 0.491670040 \\ 0.986120008 & 0.588570025 & 0.508329999 \\ 0.561389981 & 0.385120027 & 0.625110014 \\ 0.438609996 & 0.614880065 & 0.374890025 \\ 0.444170006 & 0.210860013 & 0.548570011 \\ 0.555830006 & 0.789140013 & 0.451430028\end{array}$




$\begin{array}{lll}0.624419992 & 0.177569997 & 0.534680019 \\ 0.375580030 & 0.822430051 & 0.465320020 \\ 0.681190022 & 0.285520008 & 0.683309995 \\ 0.318810001 & 0.714479999 & 0.316690002 \\ 0.741000023 & 0.353390010 & 0.586619991 \\ 0.259000011 & 0.646610041 & 0.413380006 \\ 0.332060007 & 0.722779969 & 0.158070000 \\ 0.667940034 & 0.277220006 & 0.841929976 \\ 0.409969963 & 0.855939965 & 0.113900007 \\ 0.590030012 & 0.144059998 & 0.886099990 \\ 0.567359985 & 0.877720010 & 0.299450026 \\ 0.432639983 & 0.122280016 & 0.700550013 \\ 0.472790010 & 0.909280067 & 0.374540027 \\ 0.527210026 & 0.090720023 & 0.625460054 \\ 0.555000002 & 0.017150006 & 0.311060023 \\ 0.444999985 & 0.982850010 & 0.688940016 \\ 0.299620012 & 0.031709993 & 0.418690003 \\ 0.700380074 & 0.968290025 & 0.581309994 \\ 0.263580005 & 0.036429998 & 0.546100031 \\ 0.736419997 & 0.963570028 & 0.453900008 \\ 0.066640006 & 0.818440028 & 0.299020001 \\ 0.933359998 & 0.181560002 & 0.700979996 \\ 0.043450020 & 0.819400025 & 0.432330021 \\ 0.956550002 & 0.180600024 & 0.567670018 \\ 0.170109992 & 0.801670038 & 0.401330007 \\ 0.829890030 & 0.198330011 & 0.598670032 \\ 0.104630021 & 0.830810034 & 0.614510018 \\ 0.895370040 & 0.169190015 & 0.385490021 \\ 0.258109992 & 0.934030044 & 0.605220049 \\ 0.741890082 & 0.065970013 & 0.394780032 \\ 0.180110004 & 0.696620002 & 0.510500035 \\ 0.819890065 & 0.303380024 & 0.489500004 \\ 0.176370027 & 0.679110038 & 0.644290007 \\ 0.823630000 & 0.320890022 & 0.355710032 \\ 0.329729969 & 0.784979984 & 0.633830026 \\ 0.670270032 & 0.215020021 & 0.366170013 \\ 0.941309950 & 0.381490002 & 0.791939998 \\ 0.058689967 & 0.618510005 & 0.208060000 \\ 0.928489963 & 0.495810034 & 0.741180057 \\ 0.071510021 & 0.504190047 & 0.258820003 \\ 0.993600023 & 0.371529990 & 0.608970001 \\ 0.006399989 & 0.628470036 & 0.391030038 \\ 0.131210011 & 0.422890038 & 0.729580037 \\ 0.868789982 & 0.577110020 & 0.270420023\end{array}$




$\begin{array}{lll}0.127640024 & 0.543240053 & 0.683070039 \\ 0.872360007 & 0.456759973 & 0.316930000 \\ 0.640690042 & 0.385679994 & 0.982960025 \\ 0.359309985 & 0.614319983 & 0.017040000 \\ 0.598890017 & 0.504339997 & 0.996650013 \\ 0.401110012 & 0.495660018 & 0.003350000 \\ 0.558610067 & 0.366370001 & 0.788020056 \\ 0.441390009 & 0.633629991 & 0.211980003 \\ 0.734870048 & 0.457830047 & 0.830900038 \\ 0.265130013 & 0.542169985 & 0.169100011 \\ 0.656310025 & 0.543890020 & 0.831340040 \\ 0.343690029 & 0.456110012 & 0.168660009 \\ 0.553789960 & 0.558780020 & 0.231340025 \\ 0.446210022 & 0.441220026 & 0.768660056 \\ 0.696680050 & 0.597329982 & 0.198630015 \\ 0.303320016 & 0.402670021 & 0.801370065 \\ 0.692829991 & 0.509160005 & 0.347950031 \\ 0.307169988 & 0.490839965 & 0.652050029 \\ 0.680820010 & 0.630389987 & 0.441000020 \\ 0.319180009 & 0.369609996 & 0.559000019 \\ 0.828970067 & 0.680630023 & 0.410820022 \\ 0.171030022 & 0.319370025 & 0.589180017 \\ 0.397259997 & 0.704900023 & 0.758240025 \\ 0.602739986 & 0.295100004 & 0.241760014 \\ 0.333959993 & 0.670500015 & 0.867100006 \\ 0.666040044 & 0.329499997 & 0.132900001 \\ 0.461010018 & 0.922770074 & 0.877380021 \\ 0.538989996 & 0.077230002 & 0.122620008 \\ 0.605910035 & 0.930170034 & 0.940840070 \\ 0.394090009 & 0.069830004 & 0.059160006 \\ 0.488050023 & 0.896499989 & 0.007940000 \\ 0.511950027 & 0.103500043 & 0.992060050 \\ 0.216820007 & 0.410080014 & 0.321300004 \\ 0.783180060 & 0.589920015 & 0.678699994 \\ 0.534219999 & 0.322549999 & 0.425220024 \\ 0.465779992 & 0.677450006 & 0.574780015 \\ 0.263220011 & 0.866370061 & 0.209830005 \\ 0.736779973 & 0.133630019 & 0.790170054 \\ 0.151669998 & 0.097890000 & 0.433820016 \\ 0.848330111 & 0.902110049 & 0.566180023 \\ 0.292249997 & 0.956190029 & 0.798090005 \\ 0.707750014 & 0.043810004 & 0.201910013 \\ 0.124129998 & 0.607789999 & 0.913160025 \\ 0.875869919 & 0.392209999 & 0.086839998\end{array}$




$\begin{array}{lll}0.828279963 & 0.603209959 & 0.086410005 \\ 0.171720033 & 0.396790050 & 0.913590091 \\ 0.693470047 & 0.786530042 & 0.282880009 \\ 0.306530023 & 0.213470016 & 0.717120051 \\ 0.524100023 & 0.664960004 & 0.885529992 \\ 0.475899981 & 0.335040025 & 0.114470005 \\ 0.858630009 & 0.015289998 & 0.133149997 \\ 0.141369965 & 0.984709958 & 0.866850032 \\ 0.151210016 & 0.903880065 & 0.065550001 \\ 0.848790032 & 0.096120042 & 0.934450023 \\ 0.122040008 & 0.077580002 & 0.240880010 \\ 0.877960052 & 0.922420112 & 0.759120029 \\ 0.088430007 & 0.258600000 & 0.127360006 \\ 0.911570068 & 0.741400044 & 0.872640023 \\ 0.276219986 & 0.185220013 & 0.123900000 \\ 0.723780010 & 0.814780054 & 0.876100008 \\ 0.889600013 & 0.812950025 & 0.100580003 \\ 0.110399994 & 0.187049997 & 0.899420026 \\ 0.921070027 & 0.938700058 & 0.349200028 \\ 0.078930015 & 0.061300022 & 0.650800031 \\ 0.395969978 & 0.099690003 & 0.296600033 \\ 0.604030019 & 0.900310013 & 0.703400006 \\ 0.196499960 & 0.787360022 & 0.864629984 \\ 0.803499963 & 0.212640003 & 0.135370003 \\ 0.373930020 & 0.365200024 & 0.378110012 \\ 0.626070023 & 0.634800046 & 0.621890027 \\ 0.980449953 & 0.613090011 & 0.000540000 \\ 0.019550031 & 0.386910047 & 0.999460014 \\ 0.619830060 & 0.747140034 & 0.086499999 \\ 0.380170002 & 0.252860036 & 0.913500087 \\ 0.000000000 & 0.000000000 & 0.000000000 \\ & & \end{array}$

(3) at $25 \mathrm{GPa}$

1.0

\begin{tabular}{|c|c|c|c|c|}
\hline \multicolumn{3}{|c|}{11.7012996674} & 0.0000000000 & 0.0000000000 \\
\hline \multicolumn{3}{|c|}{-5.7722486785} & 10.2893923202 & 0.0000000000 \\
\hline \multicolumn{3}{|c|}{-2.3777669999} & -4.7584418400 & 10.7827648700 \\
\hline $\mathrm{C}$ & $\mathrm{H}$ & $\mathrm{Au}$ & & \\
\hline 36 & $90 \quad 18$ & 25 & & \\
\hline \multicolumn{5}{|l|}{ ect } \\
\hline \multicolumn{2}{|c|}{0.089690001} & & 0.316179986 & 0.397899988 \\
\hline \multicolumn{2}{|c|}{0.910309971} & & 0.683819978 & 0.602099971 \\
\hline \multicolumn{2}{|c|}{0.062329999} & & 0.421050023 & 0.454939986 \\
\hline \multicolumn{2}{|c|}{0.937669924} & & 0.578949988 & 0.545059973 \\
\hline
\end{tabular}




$\begin{array}{lll}0.570620009 & 0.292099999 & 0.554629958 \\ 0.429379966 & 0.707899991 & 0.445369957 \\ 0.694769997 & 0.284549987 & 0.595739984 \\ 0.305229943 & 0.715449954 & 0.404259975 \\ 0.391830019 & 0.848829999 & 0.220459985 \\ 0.608169920 & 0.151169969 & 0.779539931 \\ 0.497179997 & 0.940900031 & 0.351519986 \\ 0.502819967 & 0.059099970 & 0.648479952 \\ 0.205969964 & 0.996529954 & 0.448529984 \\ 0.794030027 & 0.003469987 & 0.551469975 \\ 0.101729973 & 0.840970019 & 0.390299968 \\ 0.898269884 & 0.159029981 & 0.609699992 \\ 0.224539931 & 0.863639962 & 0.635669986 \\ 0.775459983 & 0.136359991 & 0.364329974 \\ 0.240989985 & 0.746370001 & 0.631319985 \\ 0.759010040 & 0.253630010 & 0.368679975 \\ 0.003440018 & 0.497870017 & 0.786290001 \\ 0.996559900 & 0.502129935 & 0.213709980 \\ 0.051439998 & 0.450099999 & 0.692419975 \\ 0.948560016 & 0.549899989 & 0.307579985 \\ 0.669539926 & 0.459199957 & 0.955139939 \\ 0.330460009 & 0.540799975 & 0.044859999 \\ 0.684640018 & 0.458499998 & 0.836589967 \\ 0.315359998 & 0.541499985 & 0.163409982 \\ 0.631939968 & 0.648119968 & 0.354599993 \\ 0.368059984 & 0.351879997 & 0.645399967 \\ 0.736140046 & 0.613949998 & 0.340999976 \\ 0.263859966 & 0.386049957 & 0.658999962 \\ 0.412169940 & 0.688829974 & 0.851609935 \\ 0.587829977 & 0.311169998 & 0.148389991 \\ 0.491310047 & 0.843140055 & 0.935389968 \\ 0.508689977 & 0.156859993 & 0.064609997 \\ 0.998030036 & 0.220079991 & 0.320789984 \\ 0.001969990 & 0.779919939 & 0.679209976 \\ 0.131909986 & 0.285249996 & 0.463579979 \\ 0.868089946 & 0.714749992 & 0.536419980 \\ 0.038950004 & 0.462820001 & 0.390199982 \\ 0.961049960 & 0.537180010 & 0.609799978 \\ 0.155879994 & 0.506879971 & 0.535289971 \\ 0.844119999 & 0.493120017 & 0.464709988 \\ 0.973979910 & 0.376049981 & 0.482039990 \\ 0.026019969 & 0.623949984 & 0.517959970 \\ 0.577059978 & 0.374060003 & 0.626109995 \\ 0.422939991 & 0.625940052 & 0.373890009\end{array}$




$\begin{array}{lll}0.470020001 & 0.192479990 & 0.527999992 \\ 0.529979978 & 0.807520009 & 0.471999967 \\ 0.679680006 & 0.191020006 & 0.531310021 \\ 0.320319980 & 0.808979990 & 0.468689983 \\ 0.715210010 & 0.282730005 & 0.686809996 \\ 0.284789994 & 0.717270049 & 0.313190008 \\ 0.789009976 & 0.379610005 & 0.604089968 \\ 0.210989996 & 0.620389983 & 0.395909991 \\ 0.352659980 & 0.737980011 & 0.192349992 \\ 0.647340011 & 0.262019975 & 0.807650012 \\ 0.433350044 & 0.883920099 & 0.153529999 \\ 0.566649996 & 0.116079997 & 0.846469994 \\ 0.572200008 & 0.913600073 & 0.373939980 \\ 0.427799943 & 0.086399984 & 0.626059980 \\ 0.444220008 & 0.932380061 & 0.416519994 \\ 0.555779977 & 0.067619973 & 0.583479965 \\ 0.549469947 & 0.051209991 & 0.363139977 \\ 0.450530007 & 0.948790053 & 0.636860004 \\ 0.286909995 & 0.030889988 & 0.408999972 \\ 0.713089976 & 0.969109976 & 0.590999988 \\ 0.258989990 & 0.034460000 & 0.547450004 \\ 0.741010004 & 0.965540011 & 0.452549955 \\ 0.037909972 & 0.806739979 & 0.293839982 \\ 0.962089989 & 0.193259985 & 0.706159977 \\ 0.031579913 & 0.809509930 & 0.440769968 \\ 0.968419985 & 0.190489988 & 0.559229992 \\ 0.154980019 & 0.787490013 & 0.390299968 \\ 0.845019994 & 0.212509974 & 0.609699992 \\ 0.116749977 & 0.834110010 & 0.607290017 \\ 0.883249928 & 0.165889987 & 0.392709987 \\ 0.269760017 & 0.911240033 & 0.576639991 \\ 0.730239926 & 0.088759978 & 0.423359969 \\ 0.203419979 & 0.671479980 & 0.538339930 \\ 0.796579934 & 0.328519988 & 0.461659986 \\ 0.185630008 & 0.689820012 & 0.682900005 \\ 0.814369986 & 0.310180009 & 0.317099977 \\ 0.352690004 & 0.790750022 & 0.676630010 \\ 0.647310034 & 0.209249998 & 0.323369993 \\ 0.930410079 & 0.409110038 & 0.805800022 \\ 0.069589973 & 0.590889970 & 0.194199981 \\ 0.946339988 & 0.542930000 & 0.758389975 \\ 0.962579972 & 0.457069964 & 0.241609985 \\ 0.037420013 & 0.382690010 & 0.605289981 \\ & 0.617310001 & 0.394709979\end{array}$




$\begin{array}{lll}0.089799973 & 0.388509965 & 0.713319987 \\ 0.910199998 & 0.611490010 & 0.286679995 \\ 0.136229995 & 0.538200009 & 0.683249979 \\ 0.863770041 & 0.461800025 & 0.316749980 \\ 0.632669935 & 0.355529953 & 0.958659934 \\ 0.367330036 & 0.644470000 & 0.041340000 \\ 0.592439996 & 0.483339959 & 0.965289986 \\ 0.407559995 & 0.516659994 & 0.034709999 \\ 0.588259974 & 0.363249969 & 0.763619953 \\ 0.411740016 & 0.636750032 & 0.236379985 \\ 0.776459964 & 0.458779952 & 0.830089929 \\ 0.223539980 & 0.541220015 & 0.169909987 \\ 0.693199918 & 0.550639964 & 0.824849956 \\ 0.306800012 & 0.449360000 & 0.175150003 \\ 0.650259919 & 0.697639958 & 0.452449969 \\ 0.349739990 & 0.302359984 & 0.547549991 \\ 0.523649993 & 0.552599996 & 0.310369983 \\ 0.476349981 & 0.447399982 & 0.689629955 \\ 0.724659955 & 0.579519997 & 0.244479981 \\ 0.275339967 & 0.420479980 & 0.755519957 \\ 0.724089972 & 0.532120007 & 0.373719974 \\ 0.275909950 & 0.467879981 & 0.626279985 \\ 0.843169956 & 0.709379976 & 0.391419983 \\ 0.156829995 & 0.290619989 & 0.608579977 \\ 0.384539992 & 0.672330047 & 0.754279967 \\ 0.615459994 & 0.327670011 & 0.245719992 \\ 0.313019948 & 0.623169980 & 0.862089968 \\ 0.686979995 & 0.376830031 & 0.137909991 \\ 0.483129949 & 0.906790019 & 0.885829928 \\ 0.516870033 & 0.093210000 & 0.114169999 \\ 0.603929972 & 0.888349997 & 0.976339954 \\ 0.396070004 & 0.111650000 & 0.023660000 \\ 0.455109968 & 0.858860011 & 0.011439999 \\ 0.544889960 & 0.141139973 & 0.988559952 \\ 0.215789999 & 0.407920002 & 0.337289980 \\ 0.784209989 & 0.592079985 & 0.662709980 \\ 0.573270036 & 0.346199988 & 0.427209994 \\ 0.426729984 & 0.653799973 & 0.572790010 \\ 0.251139997 & 0.867039961 & 0.220789993 \\ 0.748859984 & 0.132959970 & 0.779209945 \\ 0.123599973 & 0.087789977 & 0.435399983 \\ 0.876389985 & 0.912210010 & 0.564599977 \\ 0.325319971 & 0.991970024 & 0.791469920 \\ 0.674680011 & 0.008030001 & 0.208529996\end{array}$




$\begin{array}{lll}0.151649944 & 0.632639999 & 0.928179899 \\ 0.848350064 & 0.367360005 & 0.071819995 \\ 0.817740010 & 0.581510023 & 0.093959996 \\ 0.182259972 & 0.418489975 & 0.906039986 \\ 0.642589975 & 0.769649996 & 0.286879967 \\ 0.357410009 & 0.230349981 & 0.713119970 \\ 0.506399965 & 0.608349957 & 0.873149931 \\ 0.493599998 & 0.391649988 & 0.126849985 \\ 0.846249990 & 0.998320026 & 0.141729990 \\ 0.153749985 & 0.001680009 & 0.858269970 \\ 0.186000031 & 0.935050049 & 0.065959995 \\ 0.813999998 & 0.064949934 & 0.934039954 \\ 0.135700002 & 0.093980000 & 0.248249986 \\ 0.864300004 & 0.906019950 & 0.751749929 \\ 0.061310001 & 0.259380025 & 0.131909995 \\ 0.938689985 & 0.740619999 & 0.868089943 \\ 0.278820012 & 0.221269994 & 0.118259996 \\ 0.721179966 & 0.778729945 & 0.881739908 \\ 0.908550021 & 0.807739984 & 0.107790001 \\ 0.091449965 & 0.192259952 & 0.892209947 \\ 0.885089899 & 0.917819935 & 0.339509976 \\ 0.114909981 & 0.082179986 & 0.660489939 \\ 0.400089986 & 0.118819983 & 0.285679977 \\ 0.599910001 & 0.881179993 & 0.714319983 \\ 0.231009919 & 0.817779968 & 0.871989983 \\ 0.768989970 & 0.182220007 & 0.128009998 \\ 0.392689991 & 0.375649955 & 0.387599984 \\ 0.607309970 & 0.624350009 & 0.612399976 \\ 0.007149976 & 0.633369970 & 0.031979999 \\ 0.992849989 & 0.366629988 & 0.968019997 \\ 0.622149971 & 0.702740002 & 0.085059999 \\ 0.377850002 & 0.297259986 & 0.914939961 \\ 0.000000000 & 0.000000000 & 0.000000000 \\ & & \end{array}$

(4) at $50 \mathrm{GPa}$

1.0

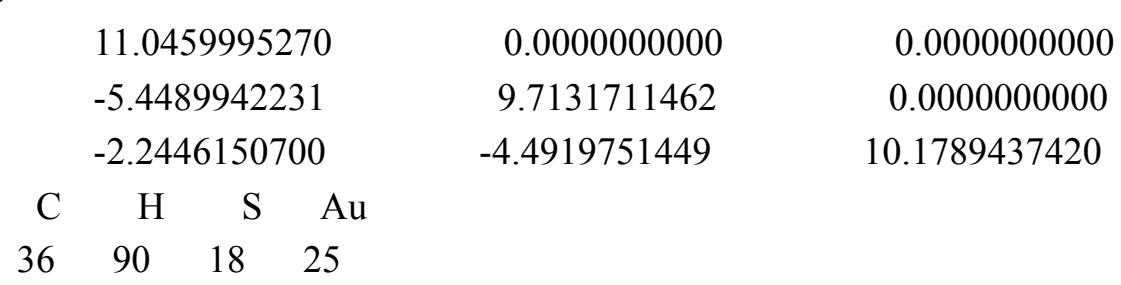

Direct
0.077859988
0.336399983
0.402130021
0.922139988
0.663600005
0.597869969 


$\begin{array}{lll}0.100759989 & 0.428889938 & 0.530029987 \\ 0.899239996 & 0.571110026 & 0.469970003 \\ 0.576359980 & 0.261809996 & 0.549680012 \\ 0.423639981 & 0.738189918 & 0.450319978 \\ 0.711530023 & 0.260799981 & 0.568429995 \\ 0.288469993 & 0.739199958 & 0.431569994 \\ 0.378490012 & 0.835860040 & 0.250899992 \\ 0.621510014 & 0.164149998 & 0.749100044 \\ 0.505259970 & 0.971539972 & 0.363190001 \\ 0.494740012 & 0.028459982 & 0.636799986 \\ 0.186719981 & 0.974269959 & 0.465429976 \\ 0.813279940 & 0.025729984 & 0.534569966 \\ 0.067670007 & 0.815630007 & 0.421449973 \\ 0.932330025 & 0.184369985 & 0.578549970 \\ 0.236169974 & 0.878339954 & 0.675790013 \\ 0.763830042 & 0.121659986 & 0.324209976 \\ 0.227019990 & 0.743399972 & 0.674129998 \\ 0.772990036 & 0.256599991 & 0.325870015 \\ 0.048499988 & 0.609379962 & 0.831650011 \\ 0.951499990 & 0.390619983 & 0.168349990 \\ 0.020710002 & 0.495779951 & 0.715529989 \\ 0.979290009 & 0.504210012 & 0.284469977 \\ 0.670159953 & 0.450939944 & 0.965849940 \\ 0.329840021 & 0.549059997 & 0.034149999 \\ 0.723309934 & 0.471489933 & 0.860899933 \\ 0.276690000 & 0.528509979 & 0.139099998 \\ 0.609139990 & 0.679250012 & 0.376639985 \\ 0.390859965 & 0.320749965 & 0.623359981 \\ 0.713030003 & 0.633830020 & 0.381590003 \\ 0.286969974 & 0.366169958 & 0.618409963 \\ 0.391160001 & 0.641170026 & 0.807640034 \\ 0.608840007 & 0.358830008 & 0.192360002 \\ 0.486589978 & 0.800050017 & 0.887260053 \\ 0.513409977 & 0.199939990 & 0.112740007 \\ 0.976239935 & 0.305379977 & 0.331420006 \\ 0.023760007 & 0.694619987 & 0.668579984 \\ 0.065119996 & 0.230919990 & 0.391479990 \\ 0.934879990 & 0.769079952 & 0.608519953 \\ 0.201769973 & 0.539199979 & 0.564839994 \\ 0.798229988 & 0.460799960 & 0.435169973 \\ 0.110559992 & 0.385599977 & 0.602479982 \\ 0.889429935 & 0.614399987 & 0.397520007 \\ 0.007919986 & 0.438029967 & 0.522679983 \\ 0.992090004 & 0.561980014 & 0.477319959\end{array}$




$\begin{array}{lll}0.589880009 & 0.335519989 & 0.639859978 \\ 0.410119982 & 0.664479965 & 0.360139988 \\ 0.472829962 & 0.153989987 & 0.518270000 \\ 0.527169951 & 0.846009940 & 0.481729990 \\ 0.686519927 & 0.149170004 & 0.542610003 \\ 0.313479969 & 0.850829997 & 0.457389986 \\ 0.786049974 & 0.327699969 & 0.669879945 \\ 0.213949979 & 0.672299948 & 0.330119998 \\ 0.772990011 & 0.312059978 & 0.512719985 \\ 0.227010005 & 0.687939961 & 0.487280004 \\ 0.360399977 & 0.736919964 & 0.261909984 \\ 0.639599982 & 0.263079978 & 0.738089959 \\ 0.392210020 & 0.830079957 & 0.158470004 \\ 0.607789979 & 0.169919964 & 0.841529997 \\ 0.590210029 & 0.955279982 & 0.403529997 \\ 0.409789983 & 0.044719982 & 0.596469993 \\ 0.464649983 & 0.999889982 & 0.436229992 \\ 0.535350002 & 0.000109981 & 0.563769997 \\ 0.552409973 & 0.066059992 & 0.335310005 \\ 0.447589991 & 0.933939975 & 0.664690032 \\ 0.268909982 & 0.001109998 & 0.420880004 \\ 0.731089973 & 0.998889904 & 0.579119985 \\ 0.247040006 & 0.024879997 & 0.570139994 \\ 0.752959969 & 0.975109927 & 0.429859995 \\ 0.999509942 & 0.766199976 & 0.317559984 \\ 0.000489979 & 0.233799966 & 0.682439958 \\ 0.996739976 & 0.812209987 & 0.475780009 \\ 0.003259987 & 0.187789992 & 0.524209955 \\ 0.108679992 & 0.750739963 & 0.442469993 \\ 0.891319981 & 0.249259977 & 0.557529997 \\ 0.133300012 & 0.871919950 & 0.662450023 \\ 0.866699969 & 0.128079986 & 0.337550013 \\ 0.266719986 & 0.900129920 & 0.596389981 \\ 0.733280015 & 0.099869989 & 0.403610009 \\ 0.132019994 & 0.645849999 & 0.592440019 \\ 0.867989969 & 0.354149977 & 0.407559970 \\ 0.223719981 & 0.729300013 & 0.764259980 \\ 0.776279942 & 0.270700000 & 0.235740009 \\ 0.327209980 & 0.752369974 & 0.666260010 \\ 0.672789945 & 0.247629988 & 0.333740003 \\ 0.949310048 & 0.568699984 & 0.855009962 \\ 0.050690025 & 0.431290022 & 0.144989993 \\ 0.086229991 & 0.710239967 & 0.811299975 \\ 0.913769988 & 0.289759991 & 0.188700003\end{array}$




$\begin{array}{lll}0.949669948 & 0.491059971 & 0.631839991 \\ 0.050329969 & 0.508939943 & 0.368159999 \\ 0.966829995 & 0.385849997 & 0.716090026 \\ 0.033170010 & 0.614149988 & 0.283910010 \\ 0.126949970 & 0.528349958 & 0.710309954 \\ 0.873049986 & 0.471650009 & 0.289689989 \\ 0.606670028 & 0.335859998 & 0.956970011 \\ 0.393330027 & 0.664139977 & 0.043030001 \\ 0.598510016 & 0.490699955 & 0.962469948 \\ 0.401499966 & 0.509299990 & 0.037530001 \\ 0.632889953 & 0.437660008 & 0.774559982 \\ 0.367110002 & 0.562339994 & 0.225439984 \\ 0.789199952 & 0.427169973 & 0.842750040 \\ 0.210799988 & 0.572829988 & 0.157249996 \\ 0.794910040 & 0.592439986 & 0.895199981 \\ 0.205089998 & 0.407559997 & 0.104799996 \\ 0.640409966 & 0.758399991 & 0.474449973 \\ 0.359589988 & 0.241599997 & 0.525550016 \\ 0.497489958 & 0.579049957 & 0.349180004 \\ 0.502510024 & 0.420950004 & 0.650820032 \\ 0.756559995 & 0.637109977 & 0.303519982 \\ 0.243439982 & 0.362889989 & 0.696479960 \\ 0.660740041 & 0.524860048 & 0.384449987 \\ 0.339259993 & 0.475139968 & 0.615549955 \\ 0.806119940 & 0.708129942 & 0.472539991 \\ 0.193869964 & 0.291869951 & 0.527459952 \\ 0.362419995 & 0.618249992 & 0.705079988 \\ 0.637579936 & 0.381749972 & 0.294920002 \\ 0.286859972 & 0.596829986 & 0.823279948 \\ 0.713139989 & 0.403159980 & 0.176709993 \\ 0.457459929 & 0.861779857 & 0.840749927 \\ 0.542539993 & 0.138209986 & 0.159250004 \\ 0.605620056 & 0.853240006 & 0.909029975 \\ 0.394379998 & 0.146760010 & 0.090979999 \\ 0.483319986 & 0.812229984 & 0.984970003 \\ 0.516679992 & 0.187759984 & 0.015030000 \\ 0.221049979 & 0.443539987 & 0.353899987 \\ 0.778949987 & 0.556459990 & 0.646099979 \\ 0.569449979 & 0.338189964 & 0.433400012 \\ 0.430549991 & 0.661809972 & 0.566600025 \\ 0.130349955 & 0.850069951 & 0.252759990 \\ 0.894269981 & 0.149929988 & 0.747239999 \\ & 0.070609988 & 0.442499974 \\ & 0.929389952 & 0.557500016\end{array}$




$\begin{array}{lll}0.381599950 & 0.028709968 & 0.824639965 \\ 0.618399973 & 0.971289974 & 0.175349999 \\ 0.199819983 & 0.671489969 & 0.971199971 \\ 0.800180016 & 0.328509987 & 0.028800000 \\ 0.810590031 & 0.571309969 & 0.123800006 \\ 0.189409993 & 0.428689967 & 0.876200031 \\ 0.601210008 & 0.770800006 & 0.273710000 \\ 0.398789968 & 0.229199971 & 0.726289966 \\ 0.478139994 & 0.553709969 & 0.848600005 \\ 0.521859983 & 0.446289951 & 0.151399996 \\ 0.818360014 & 0.991110024 & 0.120049993 \\ 0.181640000 & 0.008889995 & 0.879950008 \\ 0.166800008 & 0.903129992 & 0.071069999 \\ 0.833199956 & 0.096870007 & 0.928930014 \\ 0.129189994 & 0.089569989 & 0.256509992 \\ 0.870809890 & 0.910429976 & 0.743489974 \\ 0.062859994 & 0.252160009 & 0.151879998 \\ 0.937140055 & 0.747839977 & 0.848119933 \\ 0.290749987 & 0.249239970 & 0.128759990 \\ 0.709249970 & 0.750760010 & 0.871240035 \\ 0.908230047 & 0.794870002 & 0.103610005 \\ 0.091770006 & 0.205129989 & 0.896390043 \\ 0.859599952 & 0.893359982 & 0.315389986 \\ 0.140399985 & 0.106639971 & 0.684609980 \\ 0.385769995 & 0.111349987 & 0.281019974 \\ 0.614229944 & 0.888649928 & 0.718980015 \\ 0.351689971 & 0.901859929 & 0.968649986 \\ 0.648309995 & 0.098139997 & 0.031350000 \\ 0.384879975 & 0.377899990 & 0.392369983 \\ 0.615120008 & 0.622099960 & 0.607630030 \\ 0.025510002 & 0.621969984 & 0.082500001 \\ 0.974489935 & 0.378029964 & 0.917500006 \\ 0.624990004 & 0.697199991 & 0.074639997 \\ 0.375009991 & 0.302799983 & 0.925360016 \\ 0.000000000 & 0.000000000 & 0.000000000\end{array}$

(5) at $80 \mathrm{GPa}$

1.0

\begin{tabular}{|c|c|c|c|c|c|}
\hline \multicolumn{4}{|c|}{10.7145996094} & 0.0000000000 & 0.0000000000 \\
\hline \multicolumn{4}{|c|}{-5.2855318760} & 9.4217893445 & 0.0000000000 \\
\hline \multicolumn{4}{|c|}{-2.1772778268} & -4.3572183098 & 9.8735809119 \\
\hline $\mathrm{C}$ & $\mathrm{H}$ & $\mathrm{S}$ & $\mathrm{Au}$ & & \\
\hline & 90 & 18 & 25 & & \\
\hline
\end{tabular}




$\begin{array}{lll}0.067309978 & 0.327589982 & 0.396259998 \\ 0.932690046 & 0.672409970 & 0.603739956 \\ 0.089299985 & 0.422559986 & 0.525160000 \\ 0.910699981 & 0.577440051 & 0.474840002 \\ 0.587129996 & 0.273009995 & 0.555090022 \\ 0.412869965 & 0.726989967 & 0.444909980 \\ 0.721819977 & 0.267499997 & 0.569500011 \\ 0.278169950 & 0.732499990 & 0.430499991 \\ 0.375869967 & 0.834900006 & 0.257149988 \\ 0.624130030 & 0.165099983 & 0.742849990 \\ 0.506139987 & 0.975619937 & 0.368470015 \\ 0.493859984 & 0.024380011 & 0.631530011 \\ 0.186079958 & 0.977829979 & 0.469770024 \\ 0.813920049 & 0.022170008 & 0.530229978 \\ 0.065379992 & 0.815819975 & 0.421840012 \\ 0.934619964 & 0.184179999 & 0.578159990 \\ 0.239569989 & 0.884309993 & 0.676029973 \\ 0.760430010 & 0.115689997 & 0.323969981 \\ 0.230780003 & 0.748229955 & 0.678110006 \\ 0.769220024 & 0.251769981 & 0.321889996 \\ 0.051689987 & 0.608349997 & 0.835120061 \\ 0.948309939 & 0.391649987 & 0.164879989 \\ 0.030270008 & 0.501200005 & 0.714879990 \\ 0.969730043 & 0.498799983 & 0.285120012 \\ 0.666069977 & 0.447899987 & 0.966740044 \\ 0.333929964 & 0.552109989 & 0.033259998 \\ 0.725000030 & 0.471309960 & 0.862160010 \\ 0.274999970 & 0.528689949 & 0.137850001 \\ 0.607240007 & 0.682229974 & 0.383410009 \\ 0.392749996 & 0.317770010 & 0.616590041 \\ 0.712339945 & 0.634800002 & 0.388990023 \\ 0.287659995 & 0.365200033 & 0.611010027 \\ 0.384620023 & 0.644400022 & 0.806760037 \\ 0.615379979 & 0.355600007 & 0.193240001 \\ 0.495139997 & 0.807680025 & 0.870690030 \\ 0.504860022 & 0.192319998 & 0.129309996 \\ 0.963620016 & 0.294340010 & 0.322020004 \\ 0.036379991 & 0.705659977 & 0.677979998 \\ 0.054219992 & 0.219689997 & 0.385930003 \\ 0.945779960 & 0.780300045 & 0.614069999 \\ 0.987170013 & 0.417469980 & 0.521089954 \\ 0.012829973 & 0.582529985 & 0.478910000 \\ 0.182229985 & 0.539089966 & 0.550689981 \\ 0.817770066 & 0.460910021 & 0.449310021\end{array}$




$\begin{array}{lll}0.118479985 & 0.390799997 & 0.604390045 \\ 0.881510075 & 0.609200012 & 0.395610005 \\ 0.606980049 & 0.352640018 & 0.648769995 \\ 0.393020000 & 0.647360020 & 0.351230007 \\ 0.480899972 & 0.164629989 & 0.528740004 \\ 0.519089975 & 0.835369948 & 0.471259998 \\ 0.691640057 & 0.151309993 & 0.541299986 \\ 0.308360045 & 0.848690007 & 0.458700016 \\ 0.799830044 & 0.335130022 & 0.673340032 \\ 0.200169974 & 0.664870012 & 0.326660019 \\ 0.784499989 & 0.319319993 & 0.511870051 \\ 0.215499957 & 0.680679940 & 0.488129999 \\ 0.363249972 & 0.737239990 & 0.272010007 \\ 0.636750020 & 0.262760023 & 0.727989995 \\ 0.385709970 & 0.824020029 & 0.160439997 \\ 0.614289981 & 0.175979980 & 0.839559945 \\ 0.592139930 & 0.958689916 & 0.413370022 \\ 0.407860012 & 0.041309995 & 0.586629980 \\ 0.465380035 & 0.009560001 & 0.441650022 \\ 0.534619941 & 0.990439970 & 0.558350028 \\ 0.556179996 & 0.069079993 & 0.335929979 \\ 0.443819991 & 0.930920008 & 0.664069999 \\ 0.274820003 & 0.011820005 & 0.429030011 \\ 0.725179984 & 0.988180032 & 0.570969991 \\ 0.247320000 & 0.026579984 & 0.576899993 \\ 0.752679948 & 0.973429897 & 0.423100009 \\ 0.995359957 & 0.766860034 & 0.315569994 \\ 0.004639997 & 0.233139992 & 0.684429984 \\ 0.991750052 & 0.809930048 & 0.477089983 \\ 0.008250008 & 0.190070003 & 0.522910019 \\ 0.108439974 & 0.750479957 & 0.443390016 \\ 0.891560043 & 0.249520005 & 0.556609986 \\ 0.135400012 & 0.880439940 & 0.661340022 \\ 0.864599980 & 0.119560008 & 0.338660004 \\ 0.269039961 & 0.901319937 & 0.592719982 \\ 0.730960021 & 0.098679999 & 0.407280021 \\ 0.130320013 & 0.645550039 & 0.600489995 \\ 0.869679931 & 0.354449998 & 0.399510007 \\ 0.234630027 & 0.741050019 & 0.774110035 \\ 0.765370003 & 0.258950005 & 0.225889991 \\ 0.330220015 & 0.753449981 & 0.664449978 \\ 0.669769984 & 0.246549982 & 0.335550000 \\ 0.945429995 & 0.557940004 & 0.852290018 \\ 0.054569973 & 0.442059989 & 0.147709996\end{array}$




$\begin{array}{lll}0.095079937 & 0.714929942 & 0.817229940 \\ 0.904919987 & 0.285069992 & 0.182770001 \\ 0.958379960 & 0.502549991 & 0.633180033 \\ 0.041620001 & 0.497450018 & 0.366820018 \\ 0.976040051 & 0.385580006 & 0.707650003 \\ 0.023959957 & 0.614419981 & 0.292349999 \\ 0.141080003 & 0.540799982 & 0.712519995 \\ 0.858919984 & 0.459199998 & 0.287490004 \\ 0.598139982 & 0.329310010 & 0.956769986 \\ 0.401859998 & 0.670689996 & 0.043230001 \\ 0.596119966 & 0.492819988 & 0.959179966 \\ 0.403880004 & 0.507179983 & 0.040820000 \\ 0.641509973 & 0.461019991 & 0.780560022 \\ 0.358479991 & 0.538979982 & 0.219440005 \\ 0.781040075 & 0.415550000 & 0.833280050 \\ 0.218959987 & 0.584449976 & 0.166729997 \\ 0.814339992 & 0.593340027 & 0.911290038 \\ 0.185660000 & 0.406659977 & 0.088710000 \\ 0.638740026 & 0.763900014 & 0.483200026 \\ 0.361250025 & 0.236099998 & 0.516799976 \\ 0.493490013 & 0.578170000 & 0.355380004 \\ 0.506510027 & 0.421829998 & 0.644620022 \\ 0.773009969 & 0.656849968 & 0.320719995 \\ 0.226989984 & 0.343149975 & 0.679289979 \\ 0.650900005 & 0.515679987 & 0.372770014 \\ 0.349099991 & 0.484320000 & 0.627229988 \\ 0.793500053 & 0.692780037 & 0.489690000 \\ 0.206489993 & 0.307220018 & 0.510319999 \\ 0.322089974 & 0.599059987 & 0.700479998 \\ 0.677909978 & 0.400939989 & 0.299519980 \\ 0.299100036 & 0.626570004 & 0.851610035 \\ 0.700909941 & 0.373439989 & 0.148389991 \\ 0.464109941 & 0.873299971 & 0.828360026 \\ 0.535890007 & 0.126700003 & 0.171639988 \\ 0.613380024 & 0.852930042 & 0.880130010 \\ 0.386619992 & 0.147069997 & 0.119859995 \\ 0.513809969 & 0.831409981 & 0.977039951 \\ 0.486189987 & 0.168599997 & 0.022950000 \\ 0.215019989 & 0.442609982 & 0.352979997 \\ 0.784979995 & 0.557389980 & 0.647020005 \\ 0.584179986 & 0.352259989 & 0.436789979 \\ 0.415820007 & 0.647740036 & 0.563210023 \\ 0.225449993 & 0.848519993 & 0.261579995 \\ 0.774549982 & 0.151480020 & 0.738420007\end{array}$




$\begin{array}{lll}0.105640005 & 0.077509994 & 0.449190010 \\ 0.894350021 & 0.922489968 & 0.550809992 \\ 0.393919981 & 0.036369995 & 0.826849961 \\ 0.606079942 & 0.963629950 & 0.173150005 \\ 0.201069981 & 0.668319966 & 0.978929995 \\ 0.798929992 & 0.331679986 & 0.021080000 \\ 0.802919971 & 0.569629969 & 0.131830002 \\ 0.197079982 & 0.430369984 & 0.868170036 \\ 0.590449950 & 0.767960003 & 0.274539998 \\ 0.409550036 & 0.232040009 & 0.725460004 \\ 0.466219977 & 0.547339979 & 0.842230037 \\ 0.533779960 & 0.452659968 & 0.157769989 \\ 0.812819955 & 0.993019999 & 0.118759997 \\ 0.187180009 & 0.006980013 & 0.881240005 \\ 0.176650001 & 0.909500028 & 0.078869999 \\ 0.823350022 & 0.090489983 & 0.921129991 \\ 0.126449997 & 0.093179997 & 0.258139996 \\ 0.873549995 & 0.906830039 & 0.741859958 \\ 0.056929994 & 0.255059981 & 0.146359990 \\ 0.943069968 & 0.744940017 & 0.853640036 \\ 0.291520000 & 0.257899994 & 0.127340001 \\ 0.708479998 & 0.742099996 & 0.872659952 \\ 0.911319907 & 0.794429961 & 0.106109995 \\ 0.088690012 & 0.205570001 & 0.893890007 \\ 0.856540027 & 0.891599953 & 0.312779987 \\ 0.143460025 & 0.108400023 & 0.687219991 \\ 0.386539979 & 0.115029994 & 0.300649993 \\ 0.613460014 & 0.884970031 & 0.699350009 \\ 0.357819919 & 0.897329884 & 0.972549938 \\ 0.642180052 & 0.102659996 & 0.027450000 \\ 0.386440030 & 0.380209994 & 0.389750006 \\ 0.613560019 & 0.619790009 & 0.610260018 \\ 0.023159974 & 0.620249938 & 0.087329998 \\ 0.976840005 & 0.379749996 & 0.912669998 \\ 0.623069994 & 0.696849964 & 0.074220000 \\ 0.376929970 & 0.303150001 & 0.925779954 \\ 0.000000000 & 0.000000000 & 0.000000000\end{array}$

(6) at $110 \mathrm{GPa}$

1.0

$\begin{array}{rrr}10.4273996353 & 0.0000000000 & 0.0000000000 \\ -5.1438422674 & 9.1692188037 & 0.0000000000 \\ -2.1189188198 & -4.2404289270 & 9.6089328408\end{array}$


$\begin{array}{llll}36 & 90 & 18 & 25\end{array}$

Direct

$\begin{array}{lll}0.098790002 & 0.431680004 & 0.477839975 \\ 0.901220085 & 0.568250014 & 0.522109967 \\ 0.154390021 & 0.501420036 & 0.625829995 \\ 0.845570030 & 0.498470002 & 0.374119973 \\ 0.519829974 & 0.208469993 & 0.494559961 \\ 0.480239997 & 0.791660019 & 0.505579993 \\ 0.664830021 & 0.223359996 & 0.548509979 \\ 0.335179993 & 0.776619956 & 0.451479961 \\ 0.372190006 & 0.843689967 & 0.238360001 \\ 0.627749963 & 0.156329982 & 0.761579967 \\ 0.508979976 & 0.966929974 & 0.359659980 \\ 0.490910019 & 0.033110010 & 0.640309986 \\ 0.156729964 & 0.980650024 & 0.468049982 \\ 0.843220001 & 0.019259982 & 0.531969981 \\ 0.055180011 & 0.809480035 & 0.405869987 \\ 0.944759970 & 0.190449986 & 0.594169950 \\ 0.215700008 & 0.887700040 & 0.636399984 \\ 0.784250066 & 0.112189991 & 0.363660001 \\ 0.207069980 & 0.751319998 & 0.639619960 \\ 0.793030027 & 0.248639978 & 0.360449975 \\ 0.018430020 & 0.592650019 & 0.793470021 \\ 0.981609994 & 0.407400023 & 0.206489983 \\ 0.943600005 & 0.429939986 & 0.715279991 \\ 0.056430023 & 0.570089997 & 0.284729973 \\ 0.695089988 & 0.438990015 & 0.932369998 \\ 0.304950005 & 0.561039994 & 0.067609998 \\ 0.736840014 & 0.490289986 & 0.827549948 \\ 0.263159992 & 0.509780015 & 0.172429993 \\ 0.626160055 & 0.690660039 & 0.409759991 \\ 0.373789994 & 0.309280009 & 0.590200001 \\ 0.716660025 & 0.625310020 & 0.398399982 \\ 0.283240002 & 0.374580008 & 0.601509988 \\ 0.405010002 & 0.631749987 & 0.848749971 \\ 0.594980009 & 0.368350005 & 0.151219982 \\ 0.486740012 & 0.753500053 & 0.985750031 \\ 0.513320005 & 0.246539995 & 0.014270000 \\ 0.028679961 & 0.468689972 & 0.434679981 \\ 0.971319972 & 0.531229983 & 0.565269962 \\ 0.024660016 & 0.304410018 & 0.437579979 \\ 0.975369931 & 0.695509992 & 0.562329967 \\ 0.102379996 & 0.557129967 & 0.663219966 \\ 0.897539946 & 0.442730004 & 0.336690004\end{array}$




$\begin{array}{lll}0.275209966 & 0.593089973 & 0.662419972 \\ 0.724749984 & 0.406800017 & 0.337519996 \\ 0.136439979 & 0.416990000 & 0.668629964 \\ 0.863530039 & 0.582920023 & 0.331319978 \\ 0.519029954 & 0.272580006 & 0.587260005 \\ 0.481239983 & 0.727710026 & 0.412929995 \\ 0.410450032 & 0.092150017 & 0.440649990 \\ 0.589550003 & 0.908049957 & 0.559570009 \\ 0.668869949 & 0.123199982 & 0.541589961 \\ 0.331050067 & 0.876730086 & 0.458330009 \\ 0.707960057 & 0.295489992 & 0.653539990 \\ 0.292169992 & 0.704490031 & 0.346459999 \\ 0.744390001 & 0.289860026 & 0.507960027 \\ 0.255580014 & 0.710100011 & 0.491979990 \\ 0.350910016 & 0.733880022 & 0.239649987 \\ 0.649060002 & 0.266150000 & 0.760299956 \\ 0.380340010 & 0.850830042 & 0.141469999 \\ 0.619609990 & 0.149209979 & 0.858479919 \\ 0.580860027 & 0.927209954 & 0.396879988 \\ 0.418979955 & 0.072809987 & 0.603179947 \\ 0.463919996 & 0.986810014 & 0.436139979 \\ 0.535880016 & 0.013280009 & 0.563739993 \\ 0.566619958 & 0.076119993 & 0.347559972 \\ 0.433380027 & 0.923910081 & 0.652409944 \\ 0.274359981 & 0.028169977 & 0.469729965 \\ 0.725540005 & 0.971660064 & 0.530189955 \\ 0.176689983 & 0.016079992 & 0.574599937 \\ 0.823379996 & 0.983879984 & 0.425439974 \\ 0.999940007 & 0.763440050 & 0.294710002 \\ 0.000029981 & 0.236509998 & 0.705339983 \\ 0.969600001 & 0.771489995 & 0.453069975 \\ 0.030329983 & 0.228459987 & 0.546959962 \\ 0.120680010 & 0.760650024 & 0.424989980 \\ 0.879249951 & 0.239269976 & 0.575069979 \\ 0.103010010 & 0.871829994 & 0.625069948 \\ 0.896939923 & 0.128049999 & 0.374999987 \\ 0.256060000 & 0.909669972 & 0.556919968 \\ 0.743849989 & 0.090209993 & 0.443119993 \\ 0.123460004 & 0.653509963 & 0.542399979 \\ 0.876629957 & 0.346419966 & 0.457699978 \\ 0.170799999 & 0.733039984 & 0.722649953 \\ 0.829519999 & 0.266910004 & 0.277520000 \\ 0.319289981 & 0.766170006 & 0.662709977 \\ 0.680850056 & 0.233890008 & 0.337269989\end{array}$




$\begin{array}{lll}0.948700022 & 0.610549987 & 0.845449951 \\ 0.051329990 & 0.389479983 & 0.154499991 \\ 0.034729980 & 0.656899983 & 0.728330007 \\ 0.965360043 & 0.343159996 & 0.271639984 \\ 0.903970024 & 0.399219990 & 0.607449975 \\ 0.095960008 & 0.600730015 & 0.392549989 \\ 0.851400060 & 0.353559988 & 0.741190011 \\ 0.148680001 & 0.646570030 & 0.258929994 \\ 0.024869969 & 0.399329976 & 0.736099991 \\ 0.975139915 & 0.600680005 & 0.263889999 \\ 0.674589982 & 0.325729996 & 0.914139993 \\ 0.325480004 & 0.674310026 & 0.085829998 \\ 0.584890017 & 0.420830039 & 0.925909998 \\ 0.415110001 & 0.579129981 & 0.074050000 \\ 0.633939979 & 0.451020009 & 0.742249988 \\ 0.366039985 & 0.549130021 & 0.257799998 \\ 0.797410010 & 0.442059959 & 0.791699969 \\ 0.202500018 & 0.557960011 & 0.208159980 \\ 0.812669937 & 0.618379981 & 0.867629957 \\ 0.187390010 & 0.381690015 & 0.132390006 \\ 0.676629998 & 0.785279959 & 0.509709981 \\ 0.323329976 & 0.214619995 & 0.490280009 \\ 0.508220033 & 0.596980000 & 0.397689982 \\ 0.491689976 & 0.403010010 & 0.602240012 \\ 0.748500019 & 0.624290020 & 0.308219987 \\ 0.251469968 & 0.375619992 & 0.691719981 \\ 0.650690036 & 0.504559984 & 0.387549988 \\ 0.349170004 & 0.495299978 & 0.612280013 \\ 0.821499995 & 0.694270049 & 0.490039976 \\ 0.178379977 & 0.305539988 & 0.509899943 \\ 0.414019989 & 0.692929985 & 0.782199931 \\ 0.585780020 & 0.307260024 & 0.217859979 \\ 0.282989993 & 0.541829987 & 0.815599955 \\ 0.717030032 & 0.458180013 & 0.184429995 \\ 0.591690031 & 0.845550004 & 0.981899974 \\ 0.408390021 & 0.154489996 & 0.018139999 \\ 0.523810056 & 0.721230028 & 0.065029997 \\ 0.476190020 & 0.278740006 & 0.934949969 \\ 0.432289996 & 0.808690036 & 0.026160000 \\ 0.567789984 & 0.191370030 & 0.973879983 \\ 0.236489994 & 0.488589992 & 0.399509980 \\ 0.763569987 & 0.511470042 & 0.600489959 \\ 0.538589974 & 0.300320001 & 0.385109983 \\ 0.461479999 & 0.699720008 & 0.614959977\end{array}$




$\begin{array}{lll}0.231160026 & 0.871010051 & 0.271279984 \\ 0.768729981 & 0.128929987 & 0.728649935 \\ 0.075449999 & 0.073509992 & 0.411700006 \\ 0.924439964 & 0.926329929 & 0.588270010 \\ 0.361599989 & 0.046759968 & 0.781389962 \\ 0.638369989 & 0.953179992 & 0.218630000 \\ 0.198219992 & 0.673080032 & 0.915489974 \\ 0.801799986 & 0.326950010 & 0.084509996 \\ 0.832979969 & 0.553300042 & 0.097629995 \\ 0.167039959 & 0.446699959 & 0.902349939 \\ 0.583689953 & 0.756169951 & 0.285439998 \\ 0.416249993 & 0.243870024 & 0.714579989 \\ 0.492949991 & 0.534499982 & 0.822549946 \\ 0.507099986 & 0.465700026 & 0.177229996 \\ 0.815100036 & 0.956000001 & 0.135899999 \\ 0.184989981 & 0.044089982 & 0.864219969 \\ 0.151850011 & 0.871829987 & 0.993999982 \\ 0.848169994 & 0.128170000 & 0.006040000 \\ 0.198910003 & 0.067400003 & 0.257999984 \\ 0.801169981 & 0.932699999 & 0.742089949 \\ 0.073219993 & 0.225930004 & 0.242459991 \\ 0.926870000 & 0.774150022 & 0.757570021 \\ 0.278959974 & 0.241369992 & 0.117139993 \\ 0.721199985 & 0.758810002 & 0.882949990 \\ 0.937619998 & 0.793279984 & 0.098989994 \\ 0.062469966 & 0.206769973 & 0.901099902 \\ 0.842630031 & 0.834309973 & 0.306249999 \\ 0.157220003 & 0.165510002 & 0.693669971 \\ 0.420329993 & 0.081990001 & 0.182239985 \\ 0.579720034 & 0.918099992 & 0.817809976 \\ 0.367030007 & 0.904260004 & 0.902319966 \\ 0.633150016 & 0.095920001 & 0.097889996 \\ 0.380580006 & 0.385670018 & 0.385339991 \\ 0.619500003 & 0.614390047 & 0.614709969 \\ 0.068940032 & 0.640210009 & 0.067239999 \\ 0.930999934 & 0.359669988 & 0.932669928 \\ 0.640770058 & 0.630949990 & 0.066699993 \\ 0.359239983 & 0.369059996 & 0.933070000 \\ 0.000070000 & 0.000050000 & 0.000070000\end{array}$

